\title{
Simulating the atmospheric response to the 11-year solar cycle forcing with the UM-UKCA model: the role of detection method and natural variability
}

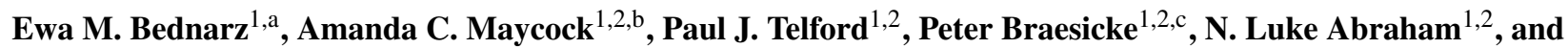 \\ John A. Pyle ${ }^{1,2}$ \\ ${ }^{1}$ Department of Chemistry, University of Cambridge, Cambridge, UK \\ ${ }^{2}$ National Centre for Atmospheric Science - Climate, Cambridge, UK \\ ${ }^{a}$ now at: Lancaster Environment Centre, Lancaster University, Lancaster, UK \\ ${ }^{b}$ now at: School of Earth and Environment, University of Leeds, Leeds, UK \\ ${ }^{c}$ now at: Karlsruhe Institute of Technology, Institute for Meteorology and Climate Research, Karlsruhe, Germany
}

Correspondence: Ewa M. Bednarz (e.bednarz@lancaster.ac.uk)

Received: 4 February 2018 - Discussion started: 26 February 2018

Revised: 27 November 2018 - Accepted: 3 December 2018 - Published: 17 April 2019

\begin{abstract}
The 11-year solar cycle forcing is recognised as an important atmospheric forcing; however, there remain uncertainties in characterising the effects of solar variability on the atmosphere from observations and models. Here we present the first detailed assessment of the atmospheric response to the 11-year solar cycle in the UM-UKCA (Unified Model coupled to the United Kingdom Chemistry and Aerosol model) chemistry-climate model (CCM) using a three-member ensemble over the recent past (1966-2010). Comparison of the model simulations is made with satellite observations and reanalysis datasets. The UM-UKCA model produces a statistically significant response to the 11-year solar cycle in stratospheric temperatures, ozone and zonal winds. However, there are also differences in magnitude, spatial structure and timing of the signals compared to observational and reanalysis estimates. This could be due to deficiencies in the model performance, and so we include a critical discussion of the model limitations, and/or uncertainties in the current observational estimates of the solar cycle signals. Importantly, in contrast to many previous studies of the solar cycle impacts, we pay particular attention to the role of the chosen analysis method in UM-UKCA by comparing the model composite and a multiple linear regression (MLR) results. We show that the stratospheric solar responses diagnosed using both techniques largely agree with each other within the associated uncertainties; however, the results show that apparently different signals can be identi-
\end{abstract}

fied by the methods in the troposphere and in the tropical lower stratosphere. Lastly, we examine how internal atmospheric variability affects the detection of the 11-year solar responses in the model by comparing the results diagnosed from the three individual ensemble members (as opposed to those diagnosed from the full ensemble). We show overall agreement between the responses diagnosed for the ensemble members in the tropical and mid-latitude mid-stratosphere to lower mesosphere but larger apparent differences at Northern Hemisphere ( $\mathrm{NH}$ ) high latitudes during the dynamically active season. Our UM-UKCA results suggest the need for long data sets for confident detection of solar cycle impacts in the atmosphere, as well as for more research on possible interdependence of the solar cycle forcing with other atmospheric forcings and processes (e.g. Quasi-Biennial Oscillation, QBO; El Niño-Southern Oscillation, ENSO).

\section{Introduction}

Incoming solar radiation plays a crucial role in controlling, amongst other things, stratospheric ozone levels and temperature. The quasi-11-year cycle in the solar irradiance has been given particular attention over the last few decades (see the reviews by Gray et al., 2010; Haigh, 2010; Solanki et al., 2013, and references therein). Here, we address this topic 
using the UM-UKCA (Unified Model coupled to the United Kingdom Chemistry and Aerosol model) chemistry-climate model (CCM). Following recent improvements in the model, we present the first detailed analysis of the atmospheric impacts of the 11-year solar cycle simulated in UM-UKCA. In contrast to many previous solar cycle modelling studies in the literature, the novel approach we take is to pay particular attention to the choice of detection method, comparing the model responses diagnosed using both a composite and a multiple linear regression (MLR) method. In addition we investigate how internal atmospheric variability affects the solar responses diagnosed in the model. Our results are particularly relevant to understanding the potential sources of uncertainty in the estimated atmospheric impacts of the 11year solar cycle forcing both in models (e.g. Mitchell et al., 2015a; Maycock et al., 2018) and observations and reanalyses (Mitchell et al., 2015b; Maycock et al., 2016).

The variation in solar spectral irradiance (SSI) as a function of wavelength is important for determining the atmospheric response to the 11-year solar cycle. Given a typical change in total solar irradiance (TSI) over the 11-year solar cycle of $\sim 1 \mathrm{~W} \mathrm{~m}^{-2}$, the associated percentage irradiance variability in the visible and infrared parts of the spectrum is relatively small while the variability in the ultraviolet (UV) region is larger (Fig. S1 in the Supplement). According to the fifth Coupled Model Intercomparison Project (CMIP5) recommendations (http://solarisheppa.geomar.de/cmip5, last access: 26 August 2016, Lean, 2000; Wang et al., 2005; Lean, 2009 ), the SSI at $\sim 220-240 \mathrm{~nm}$ varies by $\sim 3 \%-4 \%$ and at $\sim 180 \mathrm{~nm}$ by $\sim 10 \%$ (see Fig. S1). The SSI variability is even larger for wavelengths below $180 \mathrm{~nm}$, which has important consequences for mesospheric $\mathrm{O}_{2}$ absorption and resulting shortwave heating there (Nissen et al., 2007). It is now well understood that stratospheric UV absorption by ozone increases stratospheric temperatures, while the radiation at wavelengths below $\sim 242 \mathrm{~nm}$ is important for ozone production. This solar-cycle-induced ozone response provides an additional source of stratospheric heating (Haigh, 1994).

Solar-cycle-induced changes in stratospheric ozone over its 11 -year cycle of between $\sim 1 \%$ and $\sim 5 \%-6 \%$ have been reported from the analysis of various satellite (Soukharev and Hood, 2006; Tourpali et al., 2007; Dhomse et al., 2013, 2016; Maycock et al., 2016) and ground-based records (Tourpali et al., 2007). These, alongside changes in incoming solar UV radiation over the 11-year solar cycle, alter stratospheric temperatures (e.g. Gray et al., 2010). In the tropical upper stratosphere, a temperature increase of $\sim 0.7-1.1 \mathrm{~K}$ between solar maximum (SMAX) and minimum (SMIN) has been reported from rocketsonde and satellite data (Dunkerton et al., 1998; Ramaswamy et al., 2001; Keckhut et al., 2005; Randel et al., 2009; SPARC, 2010), with somewhat larger responses found in some reanalysis datasets (Frame and Gray, 2010; Mitchell et al., 2015b). In addition to the temperature and ozone responses in the mid- and upper stratosphere, secondary maxima have been identified in the tropical lower stratosphere, which are often explained to be of dynamical origin (see below).

The most frequently invoked mechanism to explain how the direct solar-cycle-induced response in the upper stratosphere can propagate down to the lower atmosphere and affect tropospheric climate is that first proposed by Kuroda and Kodera (2002) and Kodera and Kuroda (2002). In particular, Kuroda and Kodera (2002) reported the development of a positive zonal wind anomaly in the subtropical upper stratosphere for solar maximum during autumn in each hemisphere that is consistent with the strengthened horizontal temperature gradient. In that study, the positive Northern Hemisphere $(\mathrm{NH})$ zonal wind response developed and propagated poleward and downward during the course of early winter, accompanied by a relative cooling of the polar stratosphere. These early winter anomalies were followed by opposite signed responses in late winter. The authors (see also Kodera and Kuroda, 2002) postulated that the initial strengthening of the vortex near the subtropical stratopause initiates a chain of dynamical feedbacks between atmospheric planetary waves and the zonal mean flow that modulates the strength of the stratospheric jet (thereby influencing an internal mode of high-latitude stratospheric variability), with reduced upward and equatorward wave propagation associated with a stronger and colder polar vortex, and vice versa. This mechanism was developed further by Kodera and Kuroda (2002), who also postulated that the solar-cycle-induced modulation of wave activity could impact on the large-scale BrewerDobson circulation (BDC), as manifested by the weakening of both the high-latitude downwelling and the tropical upwelling in early winter (and the opposite in late winter). The authors noted that this in turn would lead to adiabatic warming and higher ozone levels in the tropical lower stratosphere in early winter, thereby accounting for the secondary temperature and ozone maxima observed in the region. It is plausible that coupling between the tropical lower stratosphere and tropospheric convection could also play a role in producing solar responses in this region (e.g. Yoo and Son, 2016).

Although there has been much progress in understanding the solar cycle impacts in the atmosphere, there remain uncertainties in both observational and model-derived estimates of the response. The observational record covers a relatively short period: only three full 11-year solar cycles have been observed in the satellite (post $\sim 1979$, e.g. SPARC, 2010) period, with a fourth observed cycle currently underway. In addition, there are observational uncertainties associated with the vertical and spatial resolution, changing instruments and scarcity of long-term measurements in certain regions, e.g. the upper stratosphere and lower mesosphere (e.g. Austin et al., 2008; SPARC, 2010; Mitchell et al., 2015b; Maycock et al., 2016). As a result, studies have found marked differences between individual datasets in terms of both the magnitude and structure of the stratospheric ozone and temperature responses to the 11-year solar cycle (e.g. Soukharev and Hood, 
2006; Mitchell et al., 2015b; Maycock et al., 2016; Dhomse et al., 2016).

Various studies have also assessed the response to an imposed solar cycle forcing in numerical models (e.g. Haigh, 1999; Matthes et al., 2004, 2013; Austin et al., 2007; Schmidt et al., 2010; Chiodo et al., 2012). While some CCMs simulate solar responses that broadly resemble the solar cycle signals derived from observations and reanalyses, some studies have found a marked spread of the solar responses between different models (e.g. Austin et al., 2008; SPARC, 2010; Hood et al., 2015; Mitchell et al., 2015a; Maycock et al., 2018). The reasons for that spread are still not properly understood.

Notably, different statistical techniques have been employed to extract the solar-cycle-induced responses from observations and model simulations, which can make it difficult to compare results between studies. Some authors composite data into bins representing periods of high and/or low solar cycle forcing (e.g. Kuroda and Kodera, 2002; van Loon et al., 2004; Chiodo et al., 2012; Matthes et al., 2013), while others use more complex statistical regression techniques (e.g. MLR) to account for the effects of different drivers (e.g:. Frame and Gray, 2010; Misios and Schmidt, 2013; Roy, 2014; Mitchell et al., 2015b; Hood et al., 2015; Maycock et al., 2016, 2018). Clearly, the use of a simpler composite methodology increases the likelihood for the solar signal to be contaminated with noise and/or the effects of other time-varying drivers, particularly in the case of small sample sizes. On the other hand, the MLR approach usually relies on the individual forcings being independent of one another and combining linearly, which might not be the case in a highly non-linear system like the atmosphere. The choice of analysis method was found to affect the derived surface responses to solar cycle (Roy and Haigh, 2010, 2012; Roy, 2014). Another related factor regarding the uncertainty in atmospheric solar responses is the potential influence of internal atmospheric variability on the signal detection, which will again be more prominent in short records.

In this paper, following recent model improvements, we present the first detailed assessment of the atmospheric response to the 11-year solar cycle simulated by an ensemble of integrations performed with the UM-UKCA chemistryclimate model. We analyse the simulated atmospheric responses to the 11-year solar cycle in UM-UKCA using both composite and MLR techniques, allowing a direct comparison of the methods. In order to understand potential limitations in deriving the solar-cycle-induced responses from records comparable in length to the current observations and reanalysis datasets, we analyse the solar cycle responses in the individual ensemble members and compare them. We note that another method for isolating the atmospheric solar cycle response in models is to use idealised time-slice integrations (e.g. Bednarz et al., 2018), but that approach is less comparable to the behaviour of the real atmosphere and is thus not considered here.
Section 2.1 describes the UM-UKCA model version used and the implementation of the 11-year solar cycle forcing in it. Section 2.2 describes the integrations performed and Sect. 2.3 the observational datasets used as a comparison to the model. Statistical analysis methods are discussed in Sect. 2.4. The yearly mean atmospheric response simulated in the model ensemble is discussed in Sect. 3, with the winter to springtime NH seasonal response discussed in Sect. 4. Section 5 contrasts the results obtained by using the composites and MLR methodologies. Section 6 focuses on the solar responses found from the individual ensemble members. Finally, Sect. 7 summarises the main results.

\section{Methodology}

\subsection{The UM-UKCA model}

\subsubsection{The base chemistry-climate model}

We use the UK Chemistry and Aerosol Model coupled to version 7.3 of the Met Office Unified Model (UM-UKCA) in the HadGEM3-A r.2.0 configuration (Hewitt et al., 2011). The configuration uses prescribed sea surface temperatures (SSTs) and sea ice. The horizontal resolution is $2.5^{\circ}$ latitude by $3.75^{\circ}$ longitude, with 60 vertical levels up to $\sim 84 \mathrm{~km}$. The time evolution of dynamical prognostic variables, with the exception of density, and the transport of chemical tracers is carried out within a semi-Lagrangian advection scheme described in Davies et al. (2005). The model includes parameterised orographic and non-orographic gravity wave drag (Scaife et al., 2002; Webster et al., 2003) and simulates an internally generated Quasi-Biennial Oscillation (QBO; Scaife et al., 2002).

The chemistry scheme used is the extended chemistry of the stratosphere scheme (CheS+, e.g. Bednarz et al., 2016). It follows from the standard stratospheric chemistry scheme (CheS) described in Morgenstern et al. (2009). However, unlike the lumping of all halogenated source gases into the three main species $\left(\mathrm{CFCl}_{3}, \mathrm{CF}_{2} \mathrm{Cl}_{2}\right.$ and $\left.\mathrm{CH}_{3} \mathrm{Br}\right)$ employed in Morgenstern et al. (2009), there are 12 halogenated source gases that are considered explicitly. In total, the chemical scheme includes 50 chemical species (out of which 46 are tracers, i.e. are transported by the circulation/mixing) and 195 chemical reactions, including 43 photolysis and 5 heterogeneous reactions. The Fast-JX photolysis scheme used is interactive; i.e. the photolysis rates are calculated accounting for changes in optical depth due to for example ozone, aerosols and clouds (Telford et al., 2013). The scheme covers the wavelengths between 177 and $850 \mathrm{~nm}$. Above $0.2 \mathrm{hPa}$ (i.e. in the mesosphere), where shorter wavelength radiation becomes more important, photolysis rates are instead calculated using lookup tables (Lary and Pyle, 1991). CheS+ includes only a simple tropospheric chemistry, including emissions of $\mathrm{NO}_{x}$ (in the form of $\mathrm{NO}$ ), $\mathrm{CO}$ and $\mathrm{HCHO}$ (Morgenstern 
Table 1. Yearly mean irradiance change between the years 1981 and $1986\left(\Delta \mathrm{TSI}=1.06 \mathrm{~W} \mathrm{~m}^{-2}\right)$ for each of the UM-UKCA shortwave heating bands.

\begin{tabular}{lll}
\hline $\begin{array}{l}\text { Spectral band } \\
\text { interval }\end{array}$ & $\begin{array}{l}\text { Absorbing } \\
\text { species }\end{array}$ & $\begin{array}{l}\text { SMAX-SMIN } \\
\text { irradiance change }\end{array}$ \\
\hline $200-320 \mathrm{~nm}$ & $\mathrm{O}_{3}$ & $0.16 \mathrm{~W} \mathrm{~m}^{-2}(0.56 \%)$ \\
$320-690 \mathrm{~nm}$ & $\mathrm{O}_{3}$ & $0.25 \mathrm{~W} \mathrm{~m}^{-2}(0.09 \%)$ \\
$320-690 \mathrm{~nm}$ & $\mathrm{O}_{3}, \mathrm{H}_{2} \mathrm{O}$ & $0.20 \mathrm{~W} \mathrm{~m}^{-2}(0.06 \%)$ \\
$0.69-1.19 \mu \mathrm{m}$ & $\mathrm{H}_{2} \mathrm{O}, \mathrm{O}_{2}$ & $0.27 \mathrm{~W} \mathrm{~m}^{-2}(0.06 \%)$ \\
$1.19-2.38 \mu \mathrm{m}$ & $\mathrm{H}_{2} \mathrm{O}, \mathrm{CO}_{2}$ & $0.15 \mathrm{~W} \mathrm{~m}^{-2}(0.06 \%)$ \\
$2.38-10.0 \mu \mathrm{m}$ & $\mathrm{H}_{2} \mathrm{O}, \mathrm{CO}_{2}$ & $0.03 \mathrm{~W} \mathrm{~m}^{-2}(0.06 \%)$ \\
\hline
\end{tabular}

et al., 2010). The emissions of ozone-depleting substances (ODSs) as well as of $\mathrm{CH}_{4}, \mathrm{~N}_{2} \mathrm{O}$ and $\mathrm{H}_{2}$ are accounted for using lower boundary concentrations. The model-calculated concentrations of $\mathrm{O}_{3}, \mathrm{~N}_{2} \mathrm{O}, \mathrm{CH}_{4}, \mathrm{CCl}_{3} \mathrm{~F}, \mathrm{CCl}_{2} \mathrm{~F}_{2}, \mathrm{C}_{2} \mathrm{Cl}_{3} \mathrm{~F}_{3}$ and $\mathrm{CHClF}_{2}$ are coupled to the radiation scheme; the specific humidity field from the physical model and prescribed $\mathrm{CO}_{2}$ concentrations are also used by the radiative scheme.

\subsubsection{The representation of the 11-year solar cycle in UM-UKCA}

The 11-year solar cycle variability has been implemented in UM-UKCA in both the radiation and photolysis schemes. This is an advance on earlier version of the model that did not include solar cycle variability (see for example SPARC, 2010). The method for implementing the solar cycle forcing in the shortwave radiation scheme follows that in the HadGEM1 (Stott et al., 2006) and HadGEM2-ES models (Jones et al., 2011). The model's radiation scheme (Edwards and Slingo, 1996) has six spectral bands from $200 \mathrm{~nm}$ to $10.0 \mu \mathrm{m}$ (Table 1) in the shortwave spectral region. The yearly mean TSI data used are those recommended for the CMIP5 simulations (Fröhlich and Lean, 1998; Lean, 2000; Wang et al., 2005; Lean, 2009), post-processed to constrain the mean over $1700-2004$ to $1365 \mathrm{~W} \mathrm{~m}^{-2}$ (Jones et al., 2011). A fit to spectral data from Lean (1995) is used to account for the change in partitioning of solar radiation into wavelength bins. Table 1 shows how the TSI change of $1.06 \mathrm{~W} \mathrm{~m}^{-2}$, i.e. the difference between the years 1981 (solar maximum) and 1986 (solar minimum), is partitioned into the individual bands of the model's shortwave radiation scheme. Using this parameterisation, the irradiance in the main UV band (200-320 nm) increases during SMAX by $\sim 0.16 \mathrm{~W} \mathrm{~m}^{-2}(0.56 \%)$. Note that this is $\sim 20 \%$ smaller than the corresponding $200-320 \mathrm{~nm}$ spectral irradiance change between these two years $\left(\sim 0.20 \mathrm{~W} \mathrm{~m}^{-2}\right)$ recommended in the more recent CMIP5 SSI specifications (Lean, 2000; Wang et al., 2005; Lean, 2009).

In the Fast-JX photolysis scheme, the change in partitioning of solar irradiance into wavelength bins is accounted for by scaling the irradiance in the 18 photolysis bins according to the difference in the yearly mean CMIP5 SSI data for the years 1981 (SMAX) and 1986 (SMIN) (see Fig. S1b) and the long-term evolution of TSI. As noted above, the FastJX scheme is used only for wavelengths between 177 and $850 \mathrm{~nm}$. At pressures less than $0.2 \mathrm{hPa}$, i.e. where photolysis rates are calculated using the lookup tables, the 11-year solar cycle variability is reflected in the TSI change only, with no modulation of the spectral distribution of solar irradiance.

\subsection{The UM-UKCA experiments}

A three-member ensemble of transient integrations covering 1960-2010 was performed. The first 6 years of each simulation were treated as spin-up and, therefore, only the 19662010 period is analysed below. With the exception of the new implementation of solar cycle variability in the model, the experimental set-up is identical to the UM-UKCA integration shown in the recent SPARC report on the Lifetimes of Stratospheric Ozone-Depleting Substances, Their Replacements, and Related Species (SPARC, 2013; Chipperfield et al., 2014). The prescribed SSTs and sea ice follow observations (Rayner et al., 2003). Greenhouse gases (GHGs) follow the SRES A1B scenario (IPCC, 2000) and ODSs follow WMO (2011). The sulfate surface area density (SAD) field recommended for the Chemistry-Climate Model Validation 2 (CCMVal2) models (SPARC, 2006; Eyring et al., 2008; Morgenstern et al., 2010) is prescribed in the stratosphere for the heterogeneous reactions on aerosol surfaces. As with previous versions of UM-UKCA, the coupling of SAD with the photolysis and radiation schemes is not included in this model version.

\subsection{The observation and reanalysis datasets}

Observed estimates of the temperature and zonal wind responses to the solar cycle forcing are derived from the ERAInterim (ERAI) reanalysis (Dee et al., 2011). We note that the existence of artificial jumps in the upper stratospheric temperature record, which can influence the diagnosed solar cycle response (see for example Hood et al., 2015; Mitchell et al., 2015b), was corrected prior to the analysis following the procedure described in McLandress et al. (2014). Although we use only one reanalysis dataset here for comparison with the model, it is important to note that there are quantitative differences in the diagnosed stratospheric responses to solar forcing amongst various current reanalyses (Mitchell et al., 2015b).

For ozone, we use the SAGE II (Stratospheric Aerosol and Gas Experiment II) ozone data in version 7.0 (Damadeo et al., 2013), which spans the period from October 1984 to August 2005. SAGE II data constitute the longest continuous record of stratospheric ozone by a single instrument; the data are characterised by a good vertical resolution of $\sim 1 \mathrm{~km}$ but a sparse horizontal sampling (Soukharev and Hood, 2006; Damadeo et al., 2013, 2014; Hood et al., 2015; Tummon et 
Solar cycle regressors

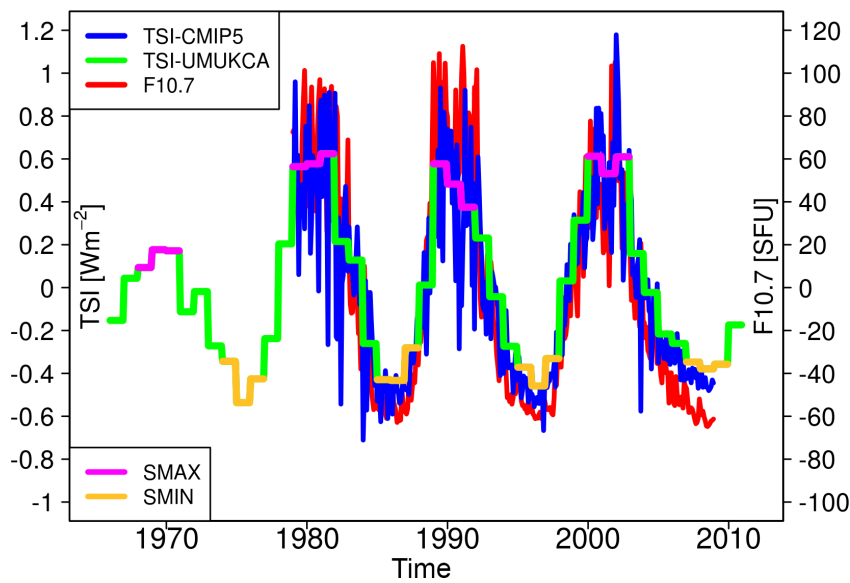

Figure 1. Time series of anomalies in TSI $\left(\mathrm{W} \mathrm{m}^{-2}\right)$ from the original CMIP5 recommendations (blue; http://solarisheppa.geomar. de/cmip5, last access: 16 April 2015; Fröhlich and Lean, 1998; Lean, 2000; Wang et al., 2005; Lean, 2009), TSI $\left(\mathrm{W} \mathrm{m}^{-2}\right)$ as given by the processed CMIP5 recommendations imposed in UMUKCA (green; Fröhlich and Lean, 1998; Lean, 2000; Wang et al., 2005; Lean, 2009; Jones et al., 2011) and the $\mathrm{F} 10.7 \mathrm{~cm}$ radio flux (SFU) (red; http://lasp.colorado.edu/lisird/tss/noaa_radio_flux. html, last access: 30 April 2015). SMAX and SMIN years used in the composite methodology are highlighted in magenta and yellow, respectively.

al., 2015). We use the units of ozone number density, as opposed to volume mixing ratios, in order to avoid uncertainties associated with the choice of temperature record used for the conversion (e.g. Maycock et al., 2016; Dhomse et al., 2016).

\subsection{The analysis methods}

We use two statistical methods for isolating the atmospheric response to the solar cycle forcing. The first is a simple composite methodology (henceforth referred to as "composites"). Data from each ensemble member are linearly detrended and 3 years of data per each SMAX and SMIN are chosen based on the three highest and three lowest yearly mean TSI values in each $\sim 11$-year cycle (Fig. 1). This gives 12 years of SMAX and 12 years of SMIN per ensemble member, resulting in 36 SMAX and 36 SMIN years for the full ensemble. A mean SMAX-SMIN difference is calculated and its magnitude scaled to represent a response per $1 \mathrm{~W} \mathrm{~m}^{-2}$ of the TSI.

The second method is a multiple linear regression technique. The MLR code is the same as that used and described in SPARC (2010), with a similar method also used in Bodeker et al. (1998) and Kunze et al. (2016). In this case, the time evolution of a variable, $y(t)$, can be defined as

$$
\begin{aligned}
y(t) & =b_{(\text {offset })} \cdot \text { offset }+b_{(\text {trend })} \cdot \operatorname{trend}(t)+b_{(\mathrm{ESC})} \cdot \operatorname{ESC}(t) \\
& +b_{(\mathrm{QBO})} \cdot \mathrm{QBO}(t)+b_{\left(\mathrm{QBO} \_ \text {orth }\right)} \cdot \mathrm{QBO} \_ \text {orth }(t) \\
& +b_{(\mathrm{ENSO})} \cdot \operatorname{ENSO}(t)+b_{(\mathrm{SAD})} \cdot \mathrm{SAD}(t) \\
& +b_{(\mathrm{TSI})} \cdot \mathrm{TSI}(t)+R(t) .
\end{aligned}
$$

The time-varying variables in Eq. (1), apart from the residual, $R(t)$, are input basis functions and the $b$ terms are the corresponding regression coefficients. $b_{\text {(offset) }} \cdot$ offset accounts for a mean annual cycle and $b_{\text {(trend) }} \cdot \operatorname{trend}(t)$ accounts for a linear trend.

For the MLR analysis of the UM-UKCA data, ESC(t) is the effective stratospheric chlorine (Eyring et al., 2007) and is defined as the global monthly mean $\mathrm{Cl}_{y}+60 \cdot \mathrm{Br}_{y}$ at $20 \mathrm{~km}$, as was done in SPARC (2010) following Newman et al. (2007). $\mathrm{Cl}_{y}$ and $\mathrm{Br}_{y}$ denote total inorganic chlorine and bromine, respectively. The $\mathrm{QBO}(t)$ term is defined by the equatorial $\left(1.5^{\circ} \mathrm{S}-1.5^{\circ} \mathrm{N}\right)$ zonal mean zonal wind at $50 \mathrm{hPa}$ and the QBO_orth $(t)$ is a function orthogonal to it. $\operatorname{ENSO}(t)$ is calculated from the model's SSTs in the form of the Nino3.4 index (e.g. Trenberth, 1997), i.e. the zonal and meridional mean SST anomaly over the $5^{\circ} \mathrm{S}-5^{\circ} \mathrm{N}, 120$ $170^{\circ} \mathrm{W}$ region, smoothed with a 5 -month running mean (here applied five times). $\operatorname{SAD}(t)$, which represents the volcanic forcing, is defined here as the $30^{\circ} \mathrm{S}-30^{\circ} \mathrm{N}$ mean of the vertical mean $(12-40 \mathrm{~km})$ sulfate SAD field. Note that, as described above, the model configuration includes volcanic aerosols only in the heterogeneous chemistry scheme and not in radiation or photolysis schemes. The solar cycle forcing is accounted for by the yearly mean TSI value used in the model to scale the amplitude of the 11-year cycle variability in both the shortwave heating and photolysis schemes (Fig. 1). We note that while some correlation between the trend and ESC functions is plausible, this is considered of secondary importance here as the study aims to isolate the solar response only.

A long-term mean is removed from all basis functions input to the MLR model apart from the offset and $\operatorname{SAD}(t)$. The $\mathrm{QBO}(t), \mathrm{QBO} \_$orth $(t)$ and $\mathrm{ENSO}(\mathrm{t})$ functions are additionally detrended. The TSI function is not detrended as the overall trend during 1966-2010 was found to be small and negative (unlike the long-term increase in TSI since the Maunder Minimum; see for example Jones et al., 2011). In order to derive the yearly mean solar response, the MLR analysis is performed using all monthly mean data and the seasonal cycle is accounted for by expanding each of the regression coefficients in a Fourier expansion into two pairs of sine and cosine functions. For calculating the regression coefficients for the individual months, the MLR analysis is carried out using monthly mean data for each individual month separately with no Fourier expansion. This makes the seasonal calculation more comparable in design to many of the previous MLR studies of the solar response (e.g. Frame and Gray, 2010; Hood et al., 2013, 2015; Mitchell et al., 2015a, 2015b; Kodera et al., 2016) as well as to the composites calculated 
here. In addition, when tested on the simulated zonal mean zonal wind and temperature data the approach was found to result in locally slightly higher $R^{2}$ values for some of the individual months than $R^{2}$ for the individual months calculated with the Fourier expansion described above (not shown). An example of a resulting fit and a residual is shown in Fig. S2.

In order to estimate the statistical significance of the derived regression coefficients, the first MLR calculation is followed by a transformation of the regression model (Markus Kunze, personal communication, 2012; Tiao et al., 1990; Bodeker et al., 1998; SPARC, 2010). In particular, a secondorder autoregressive model for the residuals is used (Eq. 2):

$R(t)=\rho_{1} R(t-1)+\rho_{2} R(t-2)+a(t)$,

where $\rho_{1}$ and $\rho_{2}$ are regression parameters and $a(t)$ is a random variable. The fitted values of $\rho_{1}$ and $\rho_{2}$ are used to transform the input basis functions and the input variable $y(t)$, and the MLR is performed again to yield the associated $t$ test statistics and/or $t$-test probabilities.

In order to derive solar regression coefficients from the full ensemble, the model output and basis functions from each of the three ensemble members were concatenated into a 135 year-long time series and the MLR was performed using the combined datasets. A similar approach has been adopted in Gray et al. (2013) and Hood et al. (2013).

For consistency with the model, the MLR analysis of ERAI and SAGE II data also employs TSI as the regressor for the solar cycle forcing. However, unlike the yearly mean TSI time series that forces the model, the time series chosen here is that originally recommended for the CMIP5 models (http: //solarisheppa.geomar.de/cmip5, last access: 16 April 2015; Fröhlich and Lean, 1998; Lean, 2000; Wang et al., 2005; Lean, 2009, Fig. 1), varying on a monthly basis. We note that a number of proxies for solar forcing have been used in the literature (see Gray et al., 2010, for details), with one of the most common being the $10.7 \mathrm{~cm}$ solar radio flux (F10.7). Figure 1 (blue and red curves) illustrates that there is a good degree of correlation between the TSI and F10.7 proxies, in particular on longer timescales $\left(R=0.81\right.$, with $1 \mathrm{~W} \mathrm{~m}^{-2}=101$ $( \pm 8)$ solar flux units, SFU).

For simplicity, the observed solar responses in ERAI and SAGE II discussed here are derived from MLR only. In this case, the volcanic regressor used, $\operatorname{SAD}(t)$, is the same as in the model. The $\mathrm{QBO}(t), \mathrm{QBO} \_$orth $(t)$ and $\operatorname{ENSO}(t)$ were calculated in the same way as in the model but using the ERAI zonal wind and SST data (Dee et al., 2011). $\operatorname{ESC}(t)$ is replaced with $\operatorname{EESC}(t)$ (equivalent effective stratospheric chlorine), which estimates stratospheric $\mathrm{Cl}_{y}$ and $\mathrm{Br}_{y}$ from their tropospheric source gases, here assuming the atmospheric circulation with the age of air spectrum with the mean of 3 years (as was done in SPARC, 2010, following Newman et al., 2007). The MLR analysis is performed over 1979-2008 for ERAI and over October 1984 to August 2005 for SAGE II.

\section{The ensemble yearly mean response in UM-UKCA}

This section focuses on the yearly mean atmospheric response to the 11-year solar cycle forcing simulated in the ensemble of the transient UM-UKCA integrations. In particular, the yearly mean changes in shortwave heating rates, temperature, ozone and zonal wind from the combined ensemble are discussed; the model responses are derived using both MLR and composites and, where available, compared with the reanalysis or observations.

\subsection{Shortwave heating rates}

Figure 2 a shows the yearly mean tropical mean $\left(25^{\circ} \mathrm{S}-\right.$ $25^{\circ} \mathrm{N}$ ) shortwave heating rate response to the 11-year solar cycle forcing in the UM-UKCA model, expressed as a response per $\mathrm{W} \mathrm{m}^{-2}$ change in TSI. The response maximises in the tropical stratopause region, reaching up to $\sim 0.16$ and $0.14 \mathrm{~K} \mathrm{day}^{-1} \mathrm{~W}^{-1} \mathrm{~m}^{2}$ for the MLR and composite methods, respectively. Notably, this solar-cycle-induced modulation constitutes a relatively small fraction of the absolute shortwave heating rates in this region $(\sim 1.5 \%$ near $50 \mathrm{~km})$. The magnitude of the MLR-derived maximum is somewhat larger than in the composites, although the two are not significantly distinguishable, in a statistical sense, given the estimated uncertainties in each.

\subsection{Temperature and zonal winds}

\subsubsection{The tropical upper stratospheric temperature response}

The corresponding yearly mean tropical temperature response to the solar cycle forcing is shown in Fig. 2b, compared with the ERAI reanalysis. The MLR tropical temperature response in UM-UKCA maximises above the stratopause at $\sim 0.8 \mathrm{~K} \mathrm{~W}^{-1} \mathrm{~m}^{2}$. In comparison, the tropical mean ERAI response maximises in the upper stratosphere at $\sim 1-1.1 \mathrm{~K} \mathrm{~W}^{-1} \mathrm{~m}^{2}$ (in agreement with previous ERAI studies, e.g. Mitchell et al., 2015b; Hood et al., 2015; Kodera et al., 2016). Compared to ERAI the UM-UKCA-simulated temperature maximum thus occurs at higher altitudes and is $\sim 25 \%$ smaller.

A number of factors could explain the apparent underestimation of the maximum tropical temperature response in UM-UKCA as compared with ERAI. One contributing factor may be the broadband shortwave heating scheme, with only one band in the UV and two in the visible parts of the spectrum (Sect. 2.1.2). Nissen et al. (2007) showed that decreasing the number of spectral bands in the UV-visible range from 49 to 6 can result in an underestimation of the stratopause shortwave heating response to the 11-year cycle by $\sim 20 \%$. In addition, only the absorption of solar radiation by ozone is considered in the first (UV) shortwave spectral band (Table 1), thereby neglecting the absorption by molecular oxygen. Also, limiting the shortwave heating scheme to 


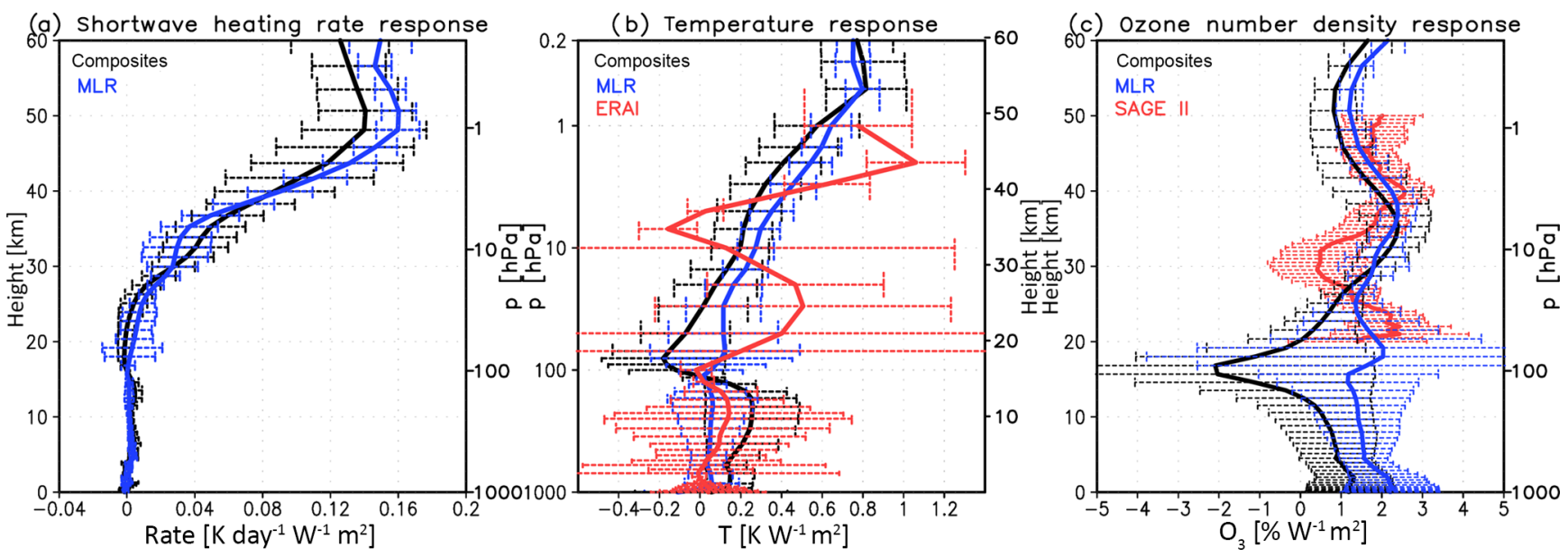

Figure 2. Yearly mean zonal mean (a) shortwave heating rate $\left(\mathrm{Kday}^{-1} \mathrm{~W}^{-1} \mathrm{~m}^{2}\right)$, (b) temperature $\left(\mathrm{KW}^{-1} \mathrm{~m}^{2}\right)$ and (c) ozone number density $\left(\% \mathrm{~W}^{-1} \mathrm{~m}^{2}\right)$ responses to the 11 -year solar cycle forcing in the tropics $\left(25^{\circ} \mathrm{S}-25^{\circ} \mathrm{N}\right)$ in UM-UKCA. The UM-UKCA responses were derived using composites (black) and MLR (blue). Shown also in red are the corresponding ERAI MLR temperature (b) and SAGE II MLR ozone (c) responses. The error bars denote the corresponding confidence intervals, represented here by \pm 2 standard errors of the mean response.

the wavelengths higher than $200 \mathrm{~nm}$ excludes changes in the mesospheric absorption by oxygen near the Lyman- $\alpha$ line $(121.6 \mathrm{~nm})$, where percentage irradiance changes during the solar cycle can be particularly large (Lean, 2000; Nissen et al., 2007).

Another factor that is likely to be important for the magnitude of the upper stratospheric temperature response is the fact that the model has used a relatively modest modulation of SSI. There has been considerable uncertainty associated with the solar cycle modulation of SSI due to the shortage of long-term satellite measurements, with marked differences between the individual available datasets (e.g. Harder et al., 2009; Dhomse et al., 2013; Ermolli et al., 2013). We also note that whilst being consistent with the design of the HadGEM2-ES model (Jones et al., 2011), the current implementation of the solar cycle forcing in the model's radiation scheme results in an underestimation of the UV changes in the $200-320 \mathrm{~nm}$ band by around $\sim 20 \%$ compared to the CMIP5 SSI recommendations (Sect. 2.1.2).

Lastly, there are large uncertainties in the reanalysis datasets in the upper stratosphere due to the scarcity of longterm measurements (McLandress et al., 2014; Long et al., 2017). As a result, large differences exist between reanalyses in both the structure and magnitude of the upper stratospheric/lower mesospheric temperature response to the solar cycle (Mitchell et al., 2015b). A somewhat smaller temperature response was estimated from the stratospheric sounding unit satellites (SPARC, 2010; Randel et al., $2009^{1}$ ), although

\footnotetext{
${ }^{1} \mathrm{Up}$ to $\sim 0.6-0.7 \mathrm{~K}$ per $100 \mathrm{SFU}, \operatorname{SPARC}$ (2010); up to $\sim$ $1 \mathrm{~K}$ per $125 \mathrm{SFU}$, Randel et al. (2009). Recall that $1 \mathrm{Wm}^{-2} \approx$ 100 SFU, Sect. 2.4 .
}

this could be related to their relatively poor vertical resolution (Gray et al., 2009).

We note that even models forced with identical SSI variations still show relatively broad ranges of solar cycle temperature responses (e.g. Austin et al., 2008; SPARC, 2010; Mitchell et al., 2015a). SPARC (2010) showed that model performance in simulating the direct radiative response to a change in solar irradiance alone could not fully account for the spread of simulated temperature responses, suggesting some contribution of indirect dynamical processes. This aspect will be investigated further in Sect. 6, where the solar response found from the individual ensemble members is considered. Lastly, the differences in stratospheric temperature responses could be related to solar ozone responses, which is discussed in Sect. 3.3.

\subsubsection{The tropical lower stratospheric temperature response}

The annual mean stratospheric temperature response to the 11-year solar cycle forcing in UM-UKCA diagnosed using MLR decreases in magnitude with decreasing altitude and does not show a secondary temperature maximum as found in ERAI in the lower stratosphere (Fig. 2b). According to the mechanism postulated by Kodera and Kuroda (2002), the anomaly results from the solar-cycle-induced modulation of the BDC brought about by the strengthened horizontal temperature gradient during the dynamically active season in each hemisphere. Thus, differences between the model and reanalysis could result from the differences in the dynamical responses. Accordingly, while ERAI shows yearly mean strengthening of the extratropical zonal winds in both hemispheres (Fig. 4c), no such yearly mean westerly anoma- 
lies were found in UM-UKCA (Fig. 4b). Instead, the yearly mean UM-UKCA-simulated response is dominated by the regions of a relative zonal wind deceleration. Therefore, any strengthening of the stratospheric vortex and the associated reduction in the large-scale circulation in UM-UKCA is too weak and/or short lived to have an impact on the tropical upwelling that would be visible in the yearly mean. Possibly, the coupling of the ocean and tropical convection, which may also play a role in influencing the tropical lower stratosphere (e.g. Yoo and Son, 2016), is also not adequately represented in the model set-up with prescribed (although observationally derived) SSTs. In the case of the Northern Hemisphere, a more detailed seasonal analysis of the simulated dynamical response is presented in Sect. 4.

One challenge for attributing signals in the tropical lower stratosphere is possible aliasing between the effects of solar forcing with other natural forcings and processes, e.g. volcanic forcing, QBO or ENSO (e.g. Lee and Smith, 2003; Marsh and Garcia, 2007; Smith and Matthes, 2008; Chiodo et al., 2014; Mitchell et al., 2015b). Chiodo et al. (2014) used the WACCM (Whole Atmosphere Community Climate Model) model and found that the secondary tropical temperature maximum widely attributed to the 11-year solar cycle over the reanalysis period largely disappeared if volcanic eruptions were not included in the model. In this version of UM-UKCA the stratospheric aerosols are coupled only to the heterogeneous chemistry scheme and not to the photolysis or radiative heating schemes; the relative overlap between the elevated values of the aerosol SAD index following the main volcanic eruptions and the years selected as composite SMAX years is also relatively small here (not shown). Therefore if aliasing with volcanic eruptions was an important contributor to the lower stratospheric temperature maximum in reanalysis, this effect would not be reproduced in UM-UKCA.

\subsubsection{The mid-latitude troposphere}

In the troposphere, ERAI shows a small warming $(\sim 0.1-$ $0.2 \mathrm{~K} \mathrm{~W}^{-1} \mathrm{~m}^{2}$ ) in the mid-latitudes on both hemispheres (Fig. 3c), accompanied by a weakening of the extratropical zonal winds at $\sim 30^{\circ}$ in the troposphere and lower stratosphere alongside somewhat weaker opposite sign responses in the mid-latitudes (Fig. 4c). These tropospheric dipole patterns represent a weakening and poleward shift of the midlatitude jets and an associated expansion of the Hadley circulation (Haigh et al., 2005; Haigh and Blackburn, 2006).

In agreement with ERAI, UM-UKCA simulates a statistically significant warming of up to $\sim 0.2 \mathrm{~K} \mathrm{~W}^{-1} \mathrm{~m}^{2}$ in the $\mathrm{NH}$ mid-latitude troposphere, detectable for both analysis methods (Fig. 3a, b). This is accompanied by a weakening of the NH extratropical zonal wind (MLR), which is broadly similar to ERAI albeit smaller in magnitude and without a strong accompanying westerly response in the mid-latitudes (Fig. 4a, b). Interestingly, the modulation of the NH subtropi-
Table 2. Yearly mean total ozone column response $\left(\mathrm{DU} \mathrm{W}^{-1} \mathrm{~m}^{2}\right)$, \pm 2 standard errors, in UM-UKCA derived using composites and MLR.

\begin{tabular}{llc}
\hline \multirow{2}{*}{ Latitude } & \multicolumn{2}{c}{$\begin{array}{c}\text { UM-UKCA total ozone } \\
\text { column response }\left(\mathrm{DU} \mathrm{W}^{-1} \mathrm{~m}^{2}\right)\end{array}$} \\
\cline { 2 - 3 } & Composites & MLR \\
\hline $25^{\circ} \mathrm{S}-25^{\circ} \mathrm{N}$ & $2.9( \pm 1.7)$ & $4.6( \pm 1.4)$ \\
$35-60^{\circ} \mathrm{N}$ & $4.8( \pm 3.3)$ & $6.1( \pm 6.5)$ \\
$35-60^{\circ} \mathrm{S}$ & $6.9( \pm 3.2)$ & $8.0( \pm 3.3)$ \\
$60^{\circ} \mathrm{S}-60^{\circ} \mathrm{N}$ & $4.1( \pm 1.9)$ & $5.6( \pm 1.4)$ \\
$90^{\circ} \mathrm{S}-90^{\circ} \mathrm{N}$ & $4.2( \pm 2.2)$ & $5.9( \pm 5.4)$ \\
\hline
\end{tabular}

cal jet in UM-UKCA occurs in the absence of a strong yearly mean tropical warming in the lower stratosphere, which has been shown to be a driver of the tropospheric wind responses (Haigh et al., 2005; Simpson et al., 2009) and/or strong yearly mean stratospheric westerly anomalies. However, Misios and Schmidt (2013) showed that a weakening and poleward shift of the subtropical jets that project onto the timescale of the solar cycle forcing could be reproduced in a model forced only with the prescribed observationally derived SSTs and sea ice. It is therefore plausible that the solar signal, or other variability, found in the prescribed observed SSTs could contribute to the diagnosed tropospheric wind changes in UM-UKCA. We note, however, that unlike the hemispherically symmetric tropospheric zonal wind and temperature response in ERAI, UM-UKCA does not capture such poleward shift of the yearly mean tropospheric jet or a mid-latitude warming in the SH. The role of prescribed SSTs in the diagnosed solar cycle response is further discussed in Sect. 6 in the context of the solar responses found in the individual ensemble members.

\subsection{Ozone}

\subsubsection{Total ozone column}

The UM-UKCA MLR results show a yearly mean global mean total column ozone response of around $\sim$ $6 \mathrm{DU} \mathrm{W}^{-1} \mathrm{~m}^{2}$ (Table 2). In comparison, total column ozone responses over the solar cycle of a few DU in the tropics and mid-latitudes have also been reported from observations (Randel and Wu, 2007; SPARC, 2010; Lean, 2014), but with some differences between the individual datasets or their different versions (Randel and Wu, 2007; Lean, 2014).

\subsubsection{The tropical/mid-latitude stratosphere}

In the tropical and mid-latitude stratosphere, the UMUKCA model simulates an ozone response of up to $~$ $2.0 \% \mathrm{~W}^{-1} \mathrm{~m}^{2}-2.5 \% \mathrm{~W}^{-1} \mathrm{~m}^{2}$ (Fig. 5a, b). The maximum ozone response in UM-UKCA is smaller than that diagnosed in SAGE II (up to $3 \% \mathrm{~W}^{-1} \mathrm{~m}^{2}-3.5 \% \mathrm{~W}^{-1} \mathrm{~m}^{2}$, Fig. $5 \mathrm{c}$; see 


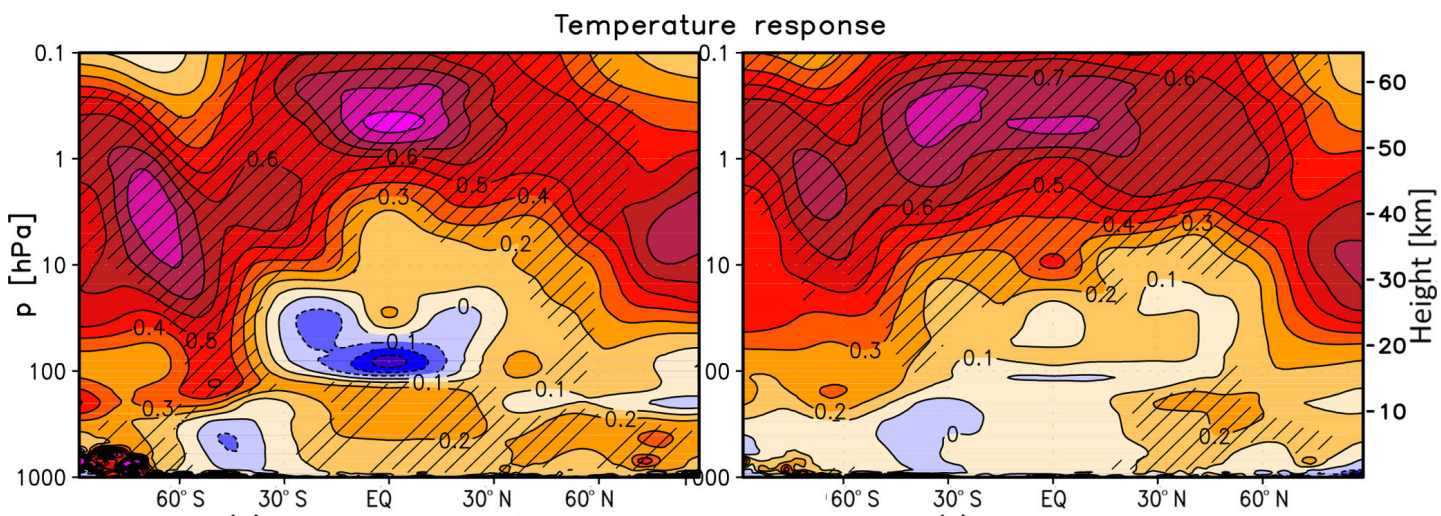

(a) UMUKCA composites

(b) UMUKCA MLR

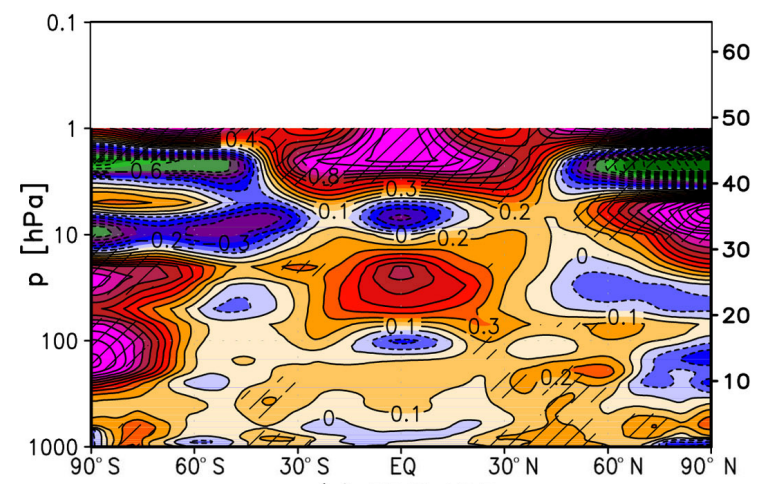

(c) ERAI MLR

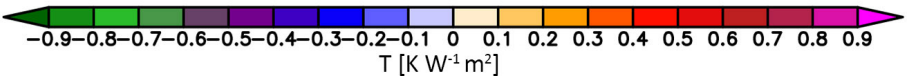

Figure 3. Yearly mean zonal mean temperature response $\left(\mathrm{K} \mathrm{W}^{-1} \mathrm{~m}^{2}\right)$ in UM-UKCA derived using composites (a) and MLR (b), as well as in ERAI derived using MLR (c). Shading indicates statistical significance on the $95 \%$ level $\left(t\right.$ test). Contour spacing is $0.1 \mathrm{~K} \mathrm{~W}^{-1} \mathrm{~m}^{2}$.

also Soukharev and Hood, 2006; Randel and Wu, 2007; Gray et al., 2009; Dhomse et al., 2013, 2016; Maycock et al., 2016) and is more uniform over the mid-stratosphere compared to the more peaked structure in the upper stratosphere in SAGE II. It also maximises at lower levels than in the observations (Figs. 2c and 5). The relatively lower altitude of the tropical ozone maximum compared to satellite observations is a common feature amongst various CCMs (Maycock et al., 2018). We note that differences exist between the magnitudes as well as the structures of the ozone responses found in different satellite products and/or their different versions (Soukharev and Hood, 2006; Dhomse et al., 2013, 2016; Maycock et al., 2016).

The lower altitude of the maximum ozone response in UM-UKCA compared to observations could contribute to the lower magnitude of the tropical temperature response. As noted in Sect. 3.2.1, there are large differences between the different SSI datasets (e.g. Ermolli et al., 2013) and the UMUKCA model is forced with relatively modest modulation of SSI at the lower end of the current estimates. Yet, the recent sensitivity study in Maycock et al. (2018) suggested a CCM forced with larger SSI variability would also produce a max- imum tropical ozone response to solar forcing at a relatively lower altitude than in satellite observations. The relatively lower altitude of the UM-UKCA model response could also arise due to model deficiencies, e.g. in the photolysis code, and/or uncertainties in the observed response. Regarding the performance of the model photolysis code, Sukhodolov et al. (2016) found a small $(\sim 0.2 \%-0.3 \%)$ underestimation of the ozone response to the solar cycle in the upper stratosphere in the Fast-JX code used in UM-UKCA compared with line-by-line calculations ${ }^{2}$; this gave rise to only a small temperature underestimation of $\sim 0.05 \mathrm{~K}$. Thus, it appears that the details of the model photolysis scheme alone cannot explain the apparent differences in the simulated tropical upper stratospheric ozone response compared to SAGE II measurements. With respect to observational uncertainties, it is important to understand that our chemistry-climate model simulates, by definition, an ozone response to the solar cycle forcing that is consistent with the imposed SSI variation and the associated changes in temperature and trans-

\footnotetext{
${ }^{2}$ For the solar cycle variability given by COSI SSI, represented as deviations in the photolysis rates of $\mathrm{O}_{2}, \mathrm{O}_{3}$ and $\mathrm{H}_{2} \mathrm{O}$ (see Sukhodolov et al., 2016, for details).
} 


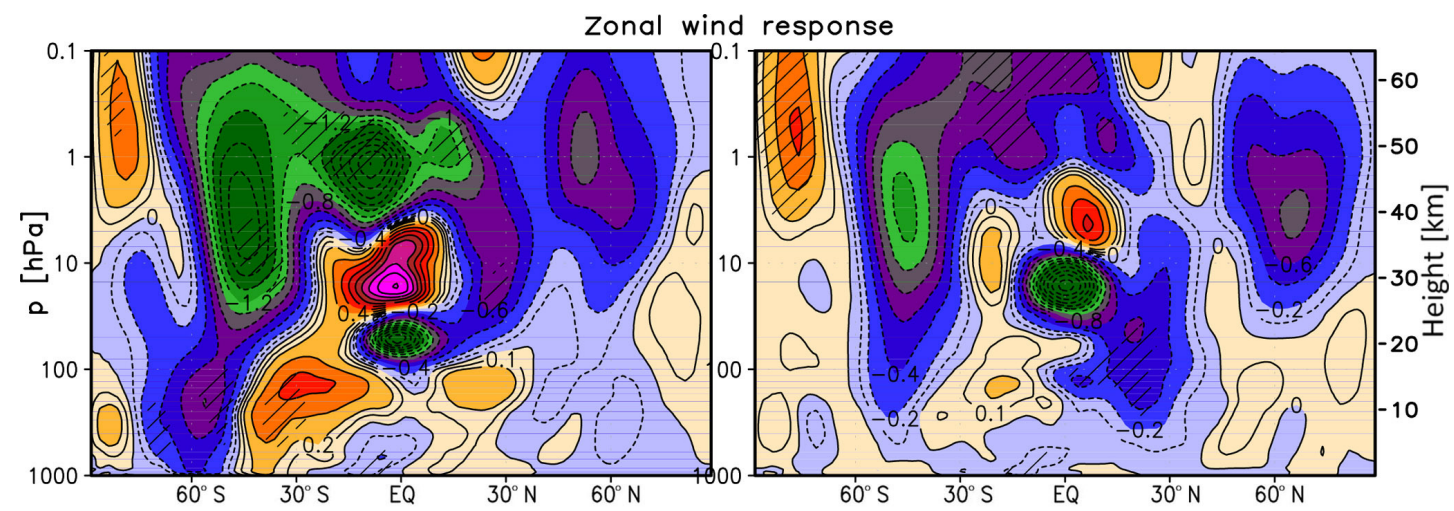

(a) UMUKCA composites

(b) UMUKCA MLR

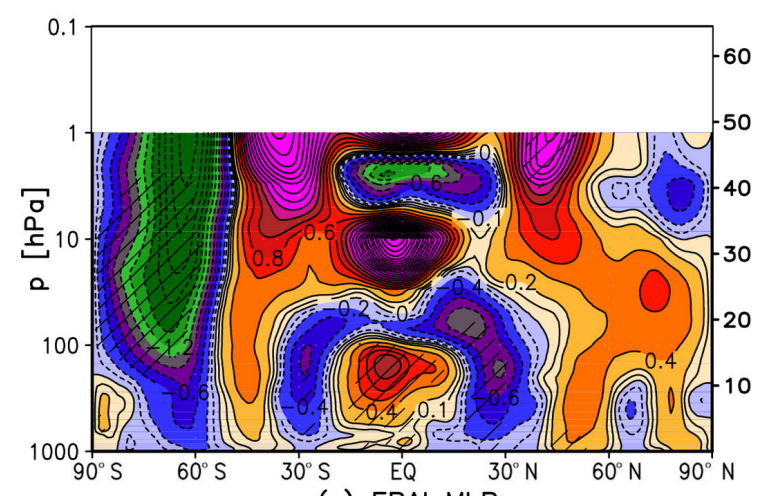

(c) ERAI MLR

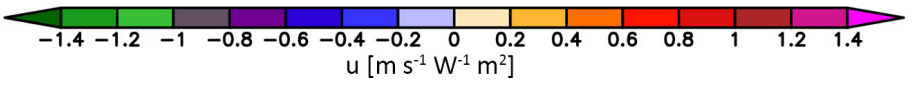

Figure 4. As in Fig. 3 but for the zonal mean zonal wind response $\left(\mathrm{m} \mathrm{s}^{-1} \mathrm{~W}^{-1} \mathrm{~m}^{2}\right)$. Contour spacing is $0.2 \mathrm{~m} \mathrm{~s}^{-1} \mathrm{~W}^{-1} \mathrm{~m}^{2}$; note also the additional contour at $\pm 0.1 \mathrm{~m} \mathrm{~s}^{-1} \mathrm{~W}^{-1} \mathrm{~m}^{2}$.

port. The modelled impact on stratospheric temperatures of the increased ozone levels under higher solar cycle activity will thus inevitably differ from that simulated by general circulation models that use prescribed observationally derived ozone changes (Maycock et al., 2018). The role of the representation of the solar-ozone feedback is discussed in detail using specially designed sensitivity experiments in Bednarz et al. (2019).

\section{The ensemble NH seasonal response in UM-UKCA}

\subsection{Temperature and zonal wind}

The previous section analysed the yearly mean zonal wind and temperature responses to the 11-year solar cycle simulated in UM-UKCA. The following section presents an analysis of the seasonal evolution of the diagnosed responses with a focus on the NH winter season. Figure 6 shows the November-April monthly mean NH temperature responses in both UM-UKCA and ERAI, and Fig. 7 shows the associated monthly mean changes in zonal wind.

\subsubsection{The ERAI reanalysis}

The enhanced solar radiation in November results in warming of the tropical and subtropical upper stratosphere (here up to $\sim 1-1.4 \mathrm{~K} \mathrm{~W}^{-1} \mathrm{~m}^{2}$ ) and a region of cooling in the polar latitudes (here up to $\sim 7 \mathrm{KW}^{-1} \mathrm{~m}^{2}$ ). The enhanced horizontal temperature gradient is commensurate with a positive zonal wind anomaly in the subtropics (as well as near the mid- to high-latitude stratopause), persisting in the subtropics throughout autumn and winter. In midwinter (January) it appears to develop and extend into the mid- and lower stratosphere and troposphere, in agreement with the postulated dynamical mechanism involving wave-mean-flow interactions (Kuroda and Kodera, 2002; Kodera and Kuroda, 2002). Notably, the zonal wind response in ERAI in January is only statistically significant near the subtropical stratopause as well as in a narrow band in the troposphere at $\sim 60^{\circ} \mathrm{N}$. In contrast, none of the changes in the stratospheric polar vortex strength or the high-latitude temperature are found to be highly statistically significant, similar to the three-reanalysismean results of Mitchell et al. (2015b). This reflects the presence of large interannual variability in the $\mathrm{NH}$ winter stratosphere resulting in large uncertainties in extracting an ob- 


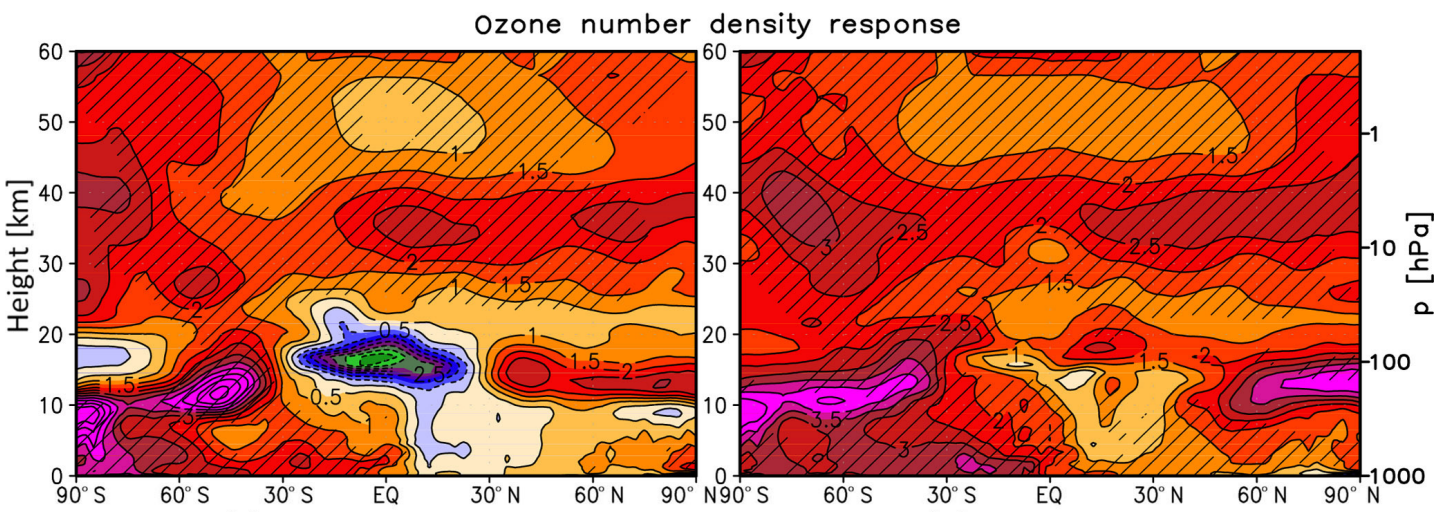

(a) UMUKCA composites

(b) UMUKCA MLR

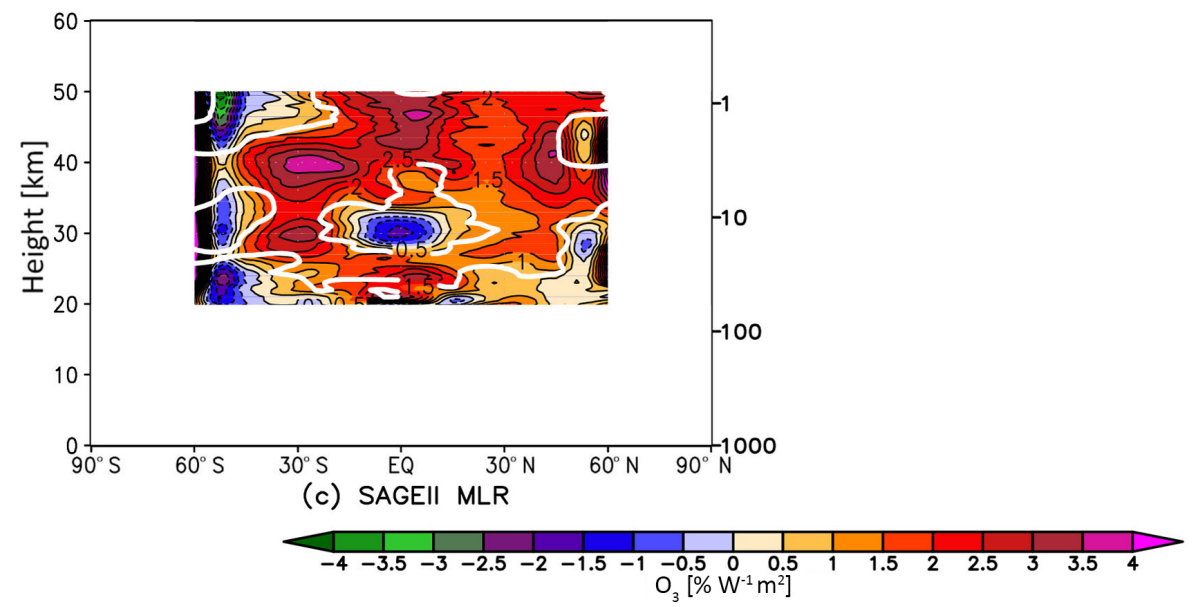

Figure 5. Yearly mean zonal mean ozone number density response $\left(\% \mathrm{~W}^{-1} \mathrm{~m}^{2}\right)$ in UM-UKCA derived using composites (a) and MLR (b), as we all as in SAGE II derived with MLR (c). The percentages are calculated relative to the mean over the 1966-2010 (a, b) and 19852004 (c) periods. Hatching in (a, b) as in Fig. 3. The thick white line in (c) encompasses regions where the statistical significance exceeds the $95 \%$ confidence level. Contour spacing is $0.5 \% \mathrm{~W}^{-1} \mathrm{~m}^{2}$ up to $\pm 7 \% \mathrm{~W}^{-1} \mathrm{~m}^{2}$.

served solar response over a relatively short time period (see also Sect. 6). In the tropical lower to mid-stratosphere (100$10 \mathrm{hPa}$ ), there is a region of warming between November and January, which contributes to the yearly mean secondary temperature maximum discussed in Sect. 3.2.

Later in February, the strengthening and cooling of the stratospheric vortex in ERAI is replaced by a stronger and statistically significant response of opposite sign. The February sign reversal has been found to be a robust feature of the various reanalysis data sets available (e.g. Matthes et al., 2004; Frame and Gray, 2010; Hood et al., 2015; Mitchell et al., 2015b; Kodera et al., 2016). Despite the sign reversal in the mid- and high latitudes, the westerly zonal wind anomaly near the subtropical stratopause persists throughout the winter into spring. It then amplifies and descends down to the stratosphere and troposphere in April, accompanied by an anomalous high-latitude cooling (where it persists at reduced magnitude until June, not shown; see also Mitchell et al., $2015 b)$. As pointed out by Mitchell et al. (2015b), despite the robustness of the response, these springtime anomalies have largely been ignored in the literature. In general, the ERAI results shown here agree with the previous reanalysis studies (e.g. Matthes et al., 2004; Frame and Gray, 2010; Mitchell et al., 2015b; Hood et al., 2015; Kodera et al., 2016).

\subsubsection{The UM-UKCA model}

The UM-UKCA results in November show a qualitatively similar but weaker pattern of temperature changes to ERAI consisting of a relative warming in the tropical upper stratosphere and lower mesosphere (up to $\sim 1 \mathrm{~K} \mathrm{~W}^{-1} \mathrm{~m}^{2}$ ) and a cooling in the polar region (of up to $\sim 1.5-2.5 \mathrm{~K} \mathrm{~W}^{-1} \mathrm{~m}^{2}$ ). The simulated strengthening of the stratospheric vortex extends down to the troposphere. The tropospheric response is stronger and more significant in the composites, and it shows $\sim 1 \mathrm{~m} \mathrm{~s}^{-1} \mathrm{~W}^{-1} \mathrm{~m}^{2}$ strengthening of the zonal wind at $\sim 60^{\circ} \mathrm{N}$ accompanied by a weakening in the subtropics. A suggestion of a small warming can be seen in the tropical lower stratosphere. However, this forms a part of a general warming throughout the depth of the tropical stratosphere 

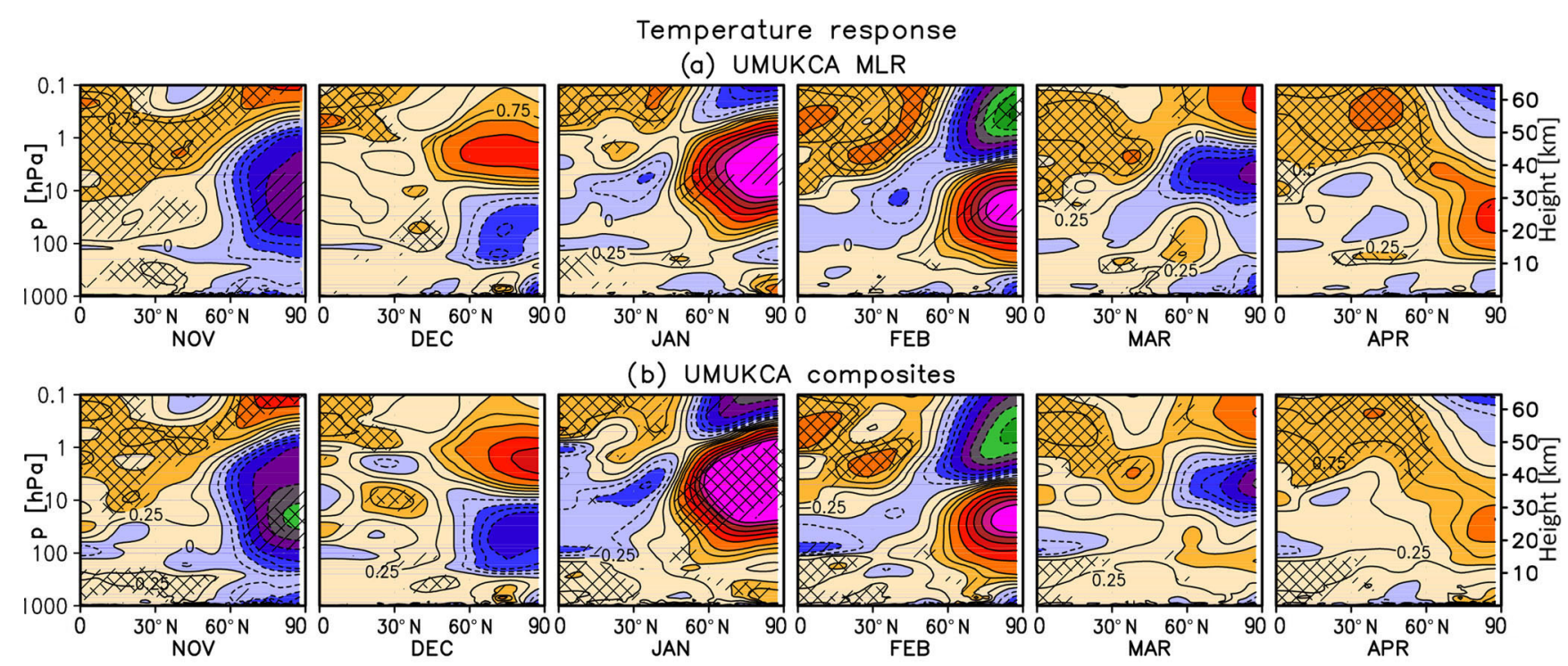

(b) UMUKCA composites
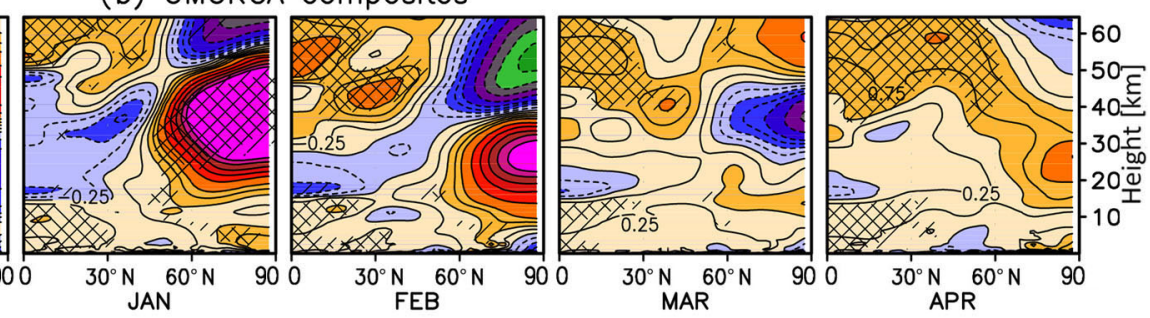

(c) ERAI MLR
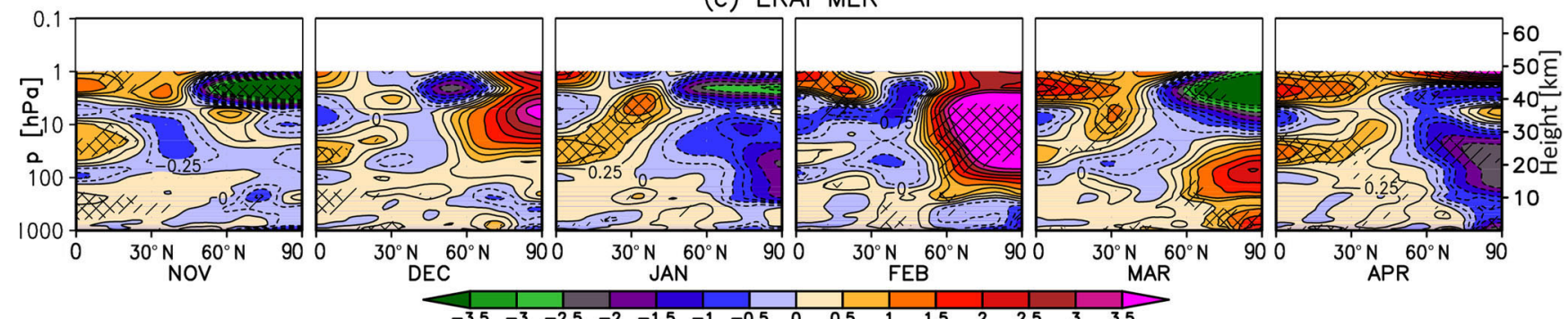

$\mathrm{T}\left[\mathrm{K} \mathrm{W}^{-1} \mathrm{~m}^{2}\right]$

Figure 6. Monthly mean November-April zonal mean temperature response $\left(\mathrm{K} \mathrm{W}^{-1} \mathrm{~m}^{2}\right)$ in UM-UKCA derived using MLR (a) and composites (b). Shown also is the ERAI response derived with MLR (c). Single and double hatching indicates statistical significance on the $90 \%$ and $95 \%$ level, respectively $\left(t\right.$ test). Note the additional contours at $\pm 0.25 \mathrm{~K} \mathrm{~W}^{-1} \mathrm{~m}^{2}$.

and is weaker than the larger and more localised response in ERAI (November-January).

In December, both the temperature and zonal wind responses simulated in UM-UKCA weaken compared to November. While some cooling remains in the polar lower stratosphere, an opposite sign response develops in the upper stratosphere aloft. In midwinter (January-February), the polar warming magnifies and descends, alongside the simulated weakening of the stratospheric jet. While the easterly anomaly propagates down through the lower mesosphere and stratosphere, the westerly response redevelops near the subtropical stratopause. It then appears to propagate poleward and, to some extent, down in the stratosphere in spring, reversing sign in April. However, the anomalies derived from MLR and composite analysis are not highly statistically significant in April, suggesting a small signal-to-noise level.

\subsubsection{Discussion}

The evolution of the solar cycle response in the NH high latitudes in winter in UM-UKCA shows a shift in the timing of the UM-UKCA-modelled responses towards earlier in the winter. In particular, the strengthening of the stratospheric vortex and its extension to the troposphere were simulated in UM-UKCA in November, with the sign reversal occurring most prominently in January. In ERAI, the indication of the poleward propagation of the subtropical westerly response can be seen later (January) with the pronounced sign reversal occurring rapidly in February. In February, the modelled anomalies agree well with the diagnosed ERAI anomalies. In addition to the different timing of the zonal wind response to ERAI, the simulated westerly response diagnosed from monthly mean data appears at higher latitudes than in ERAI, thereby not clearly reproducing the poleward and downward propagation seen in the reanalysis (although the model simulates a significant dynamical response to the imposed solar forcing at high latitudes comparable in magnitude to that diagnosed in ERAI). We also note that the westerly anomalies near the subtropical/mid-latitude stratopause found in ERAI from late autumn till spring are generally much stronger and longer-lived in the reanalysis than in UM-UKCA. Lastly, the UM-UKCA model integrations do not reproduce the westerly zonal wind anomalies found in the reanalysis in the mid- 

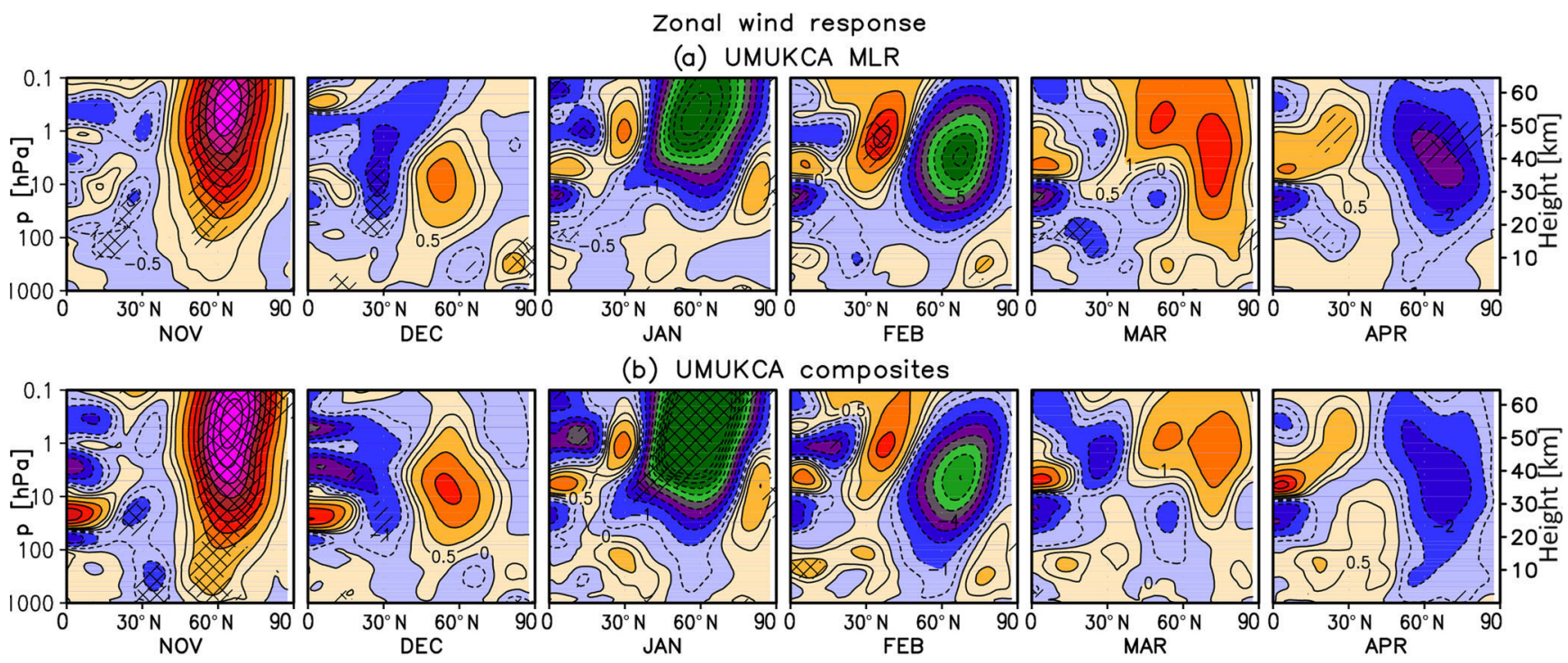

(b)
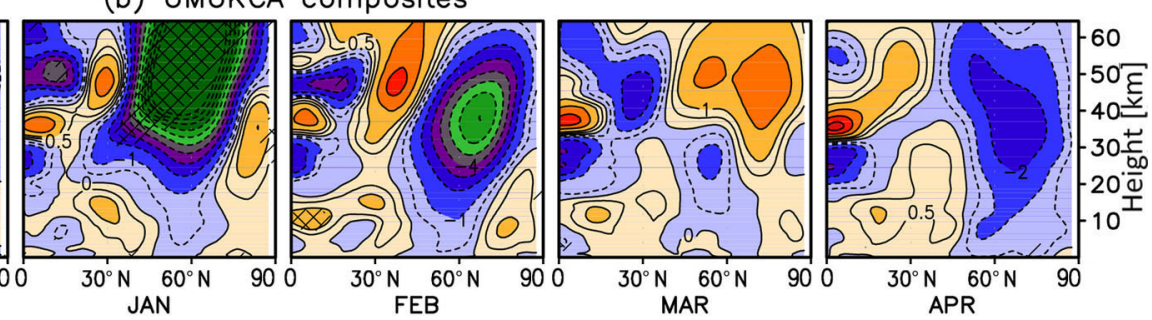

(c) ERAI MLR
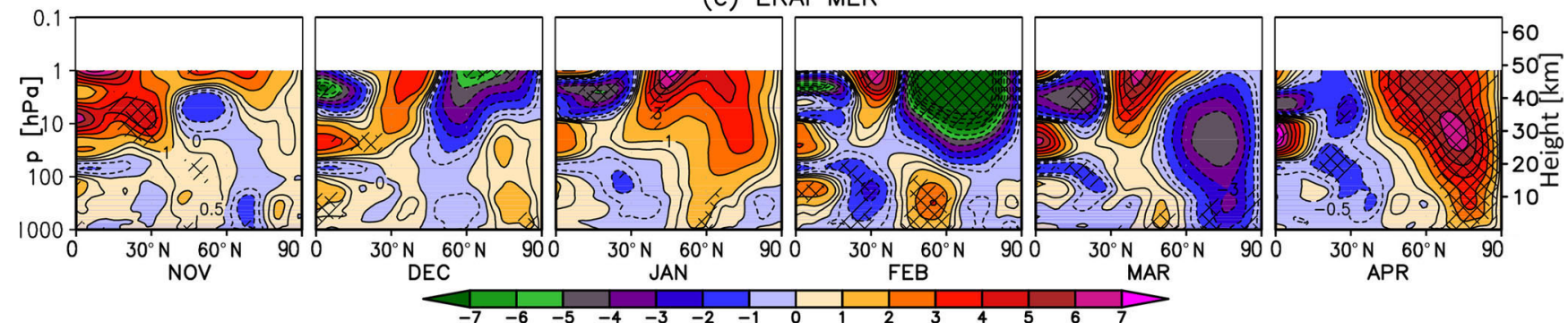

$\mathrm{u}\left[\mathrm{m} \mathrm{s}^{-1} \mathrm{~W}^{-1} \mathrm{~m}^{2}\right]$

Figure 7. As in Fig. 6 but for the zonal mean zonal wind change $\left(\mathrm{m} \mathrm{s}^{-1} \mathrm{~W}^{-1} \mathrm{~m}^{2}\right)$. Note the additional contours at $\pm 0.5, \pm 8, \pm 9$ and $\pm 10 \mathrm{~m} \mathrm{~s}^{-1} \mathrm{~W}^{-1} \mathrm{~m}^{2}$.

to late springtime (April onwards) stratosphere. Regarding the temperature anomalies simulated in the tropical lower stratosphere, while there is some general warming throughout the tropical stratosphere in UM-UKCA in November (i.e. when the largest westerly anomaly occurs in the mid- to highlatitude stratosphere), the temperature increase in the tropical lower stratosphere is very small and does not form a distinct maximum as in ERAI.

The differences in the timing of the UM-UKCA-modelled zonal wind and temperature responses compared with the reanalysis could be related to a positive bias in the background zonal wind climatology in UM-UKCA (not shown). As pointed out by Kodera and Kuroda (2002), the mechanism behind the high-latitude response to the solar cycle forcing relies on the non-linear interactions between the planetary waves and the mean flow and, therefore, is influenced by the climatological mean state. It is well known that the propagation of planetary waves through the mid- and high-latitude stratosphere is strongly dependent on the strength and direction of the background zonal wind, with the planetary waves propagating only if the winds are westerly and not too strong (Charney and Drazin, 1961; Andrews et al., 1987). The im- portance of a realistic climatology in models for reproducing the observed dynamical response to the solar cycle forcing has also been suggested by other studies, e.g. Kodera et al. (2003), Matthes et al. (2004), Rind et al. (2008), Schmidt et al. (2010) and Chiodo et al. (2012). The differences in timing could also be related to errors in the prescribed SSI forcing in UM-UKCA, which may not be representative of the true SSI variability (Ermolli et al., 2013).

\subsection{Mechanism}

As discussed in the introduction, Kuroda and Kodera (2002) and Kodera and Kuroda (2002) postulated that the initial solar-cycle-induced enhancement of the horizontal temperature gradient in autumn and the associated strengthening of the subtropical upper stratospheric jet initiate a chain of feedbacks between planetary waves and the mean flow that modulates the evolution of the polar vortex, as well as the $\mathrm{BDC}$, throughout the dynamically active season. A mechanism consistent with that was later shown to operate in a number of modelling studies (e.g. Matthes et al., 2004, 2006; Chiodo et al., 2012). 

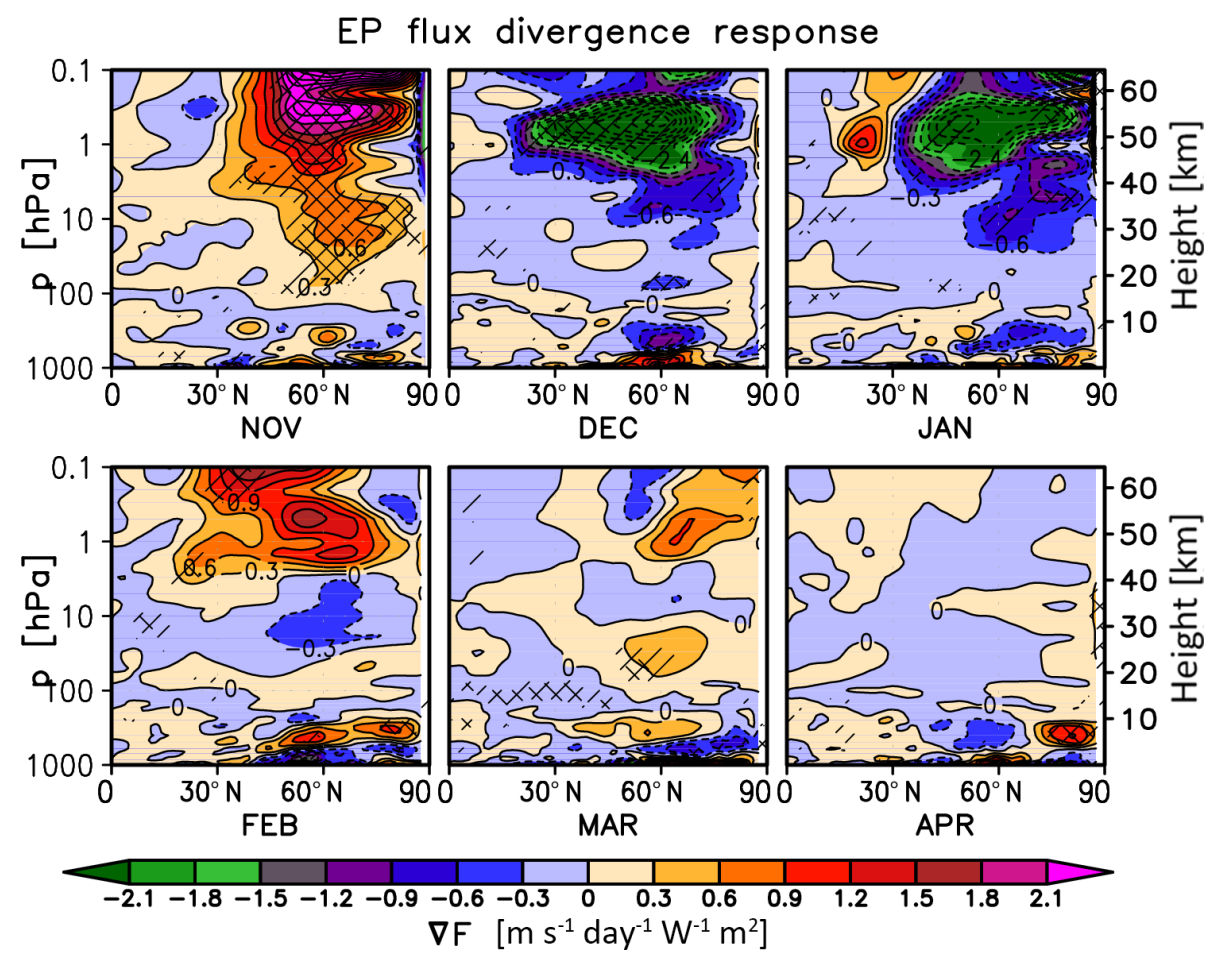

Figure 8. Monthly mean November-April scaled EP flux divergence (i.e. $(\nabla \cdot \boldsymbol{F}) /(\rho \cdot a \cdot \cos \phi)$; see Andrews et al., 1987) response $\left(\mathrm{m} \mathrm{s}^{-1} \mathrm{day}^{-1} \mathrm{~W}^{-1} \mathrm{~m}^{2}\right)$ in UM-UKCA derived with MLR. Single and double hatching indicates statistical significance on the $90 \%$ and $95 \%$ level, respectively ( $t$ test). Contour spacing is $0.3 \mathrm{~m} \mathrm{~s}^{-1}$ day ${ }^{-1} \mathrm{~W}^{-1} \mathrm{~m}^{2}$.

The changes in zonal mean circulation simulated in UM-UKCA discussed above are associated with consistent changes in wave propagation and breaking. In particular, the development of the positive zonal wind response to higher solar cycle forcing in autumn (November, Fig. 7) is associated with a decreased propagation of planetary waves through the stratosphere (not shown) and a reduction in wave breaking throughout the mid- and high-latitude stratosphere and lower mesosphere (divergence of Eliassen-Palm, EP, flux of up to $\sim 2.5 \mathrm{~m} \mathrm{~s}^{-1} \mathrm{day}^{-1} \mathrm{~W}^{-1} \mathrm{~m}^{2}$, Fig. 8). This reduction in the deposition of eddy heat and momentum accelerates the zonal wind, which should feed back on planetary waves and result in even less wave propagation and breaking. So, there is a two-way interaction between the waves and zonal wind, as also discussed in Kuroda and Kodera (2002), Kodera and Kuroda (2002), Matthes et al. (2004, 2006) and Chiodo et al. (2012).

Later in December and January, UM-UKCA simulates an increase in the mid-/high-latitude wave propagation (not shown) and increased wave breaking under higher solar cycle forcing in December and January, which is particularly evident in the upper stratosphere and lower mesosphere (see the negative divergence of EP flux, i.e. convergence, of up to $\sim 3.5-4 \mathrm{~m} \mathrm{~s}^{-1}$ day $^{-1} \mathrm{~W}^{-1} \mathrm{~m}^{2}$, Fig. 8). As this decelerates the zonal wind, the results are consistent with the considerable weakening of the westerly zonal wind response in De- cember, compared to November, and its sign reversal in January. In the subtropics, the emergence of a positive zonal wind anomaly near the stratopause in January is associated with the region of a relative EP flux divergence that develops over the mid- and high latitudes in February, consistent with the strengthening of the subtropical westerly signal in that month and its apparent poleward and downward propagation in March. However, the amplitudes of the EP flux divergence anomalies in late winter and early spring are generally smaller than earlier and not highly statistically significant.

Changes in planetary wave propagation and breaking in the high latitudes modulate the BDC. As expected, in November the strengthening of the stratospheric jet and the accompanying reduction in the mid- and high-latitude wave breaking under higher solar cycle forcing reduce downwelling in the lower and mid-stratosphere over the polar cap (Fig. 9); this in turn contributes to the high-latitude cooling modelled in the region (Fig. 6). In the tropics, we find a suggestion of a small reduction in upwelling in the lower stratosphere (below $\sim 10 \mathrm{hPa}$ ) in UM-UKCA, as postulated by the mechanism of Kodera and Kuroda (2002); however, the $\bar{w}^{*}$ response, particularly at the altitudes of $\sim 100-30 \mathrm{hPa}$, is very small and not highly statistically significant, indicating that the postulated mechanism is not robustly reproduced in the model. A more statistically robust response was found in 

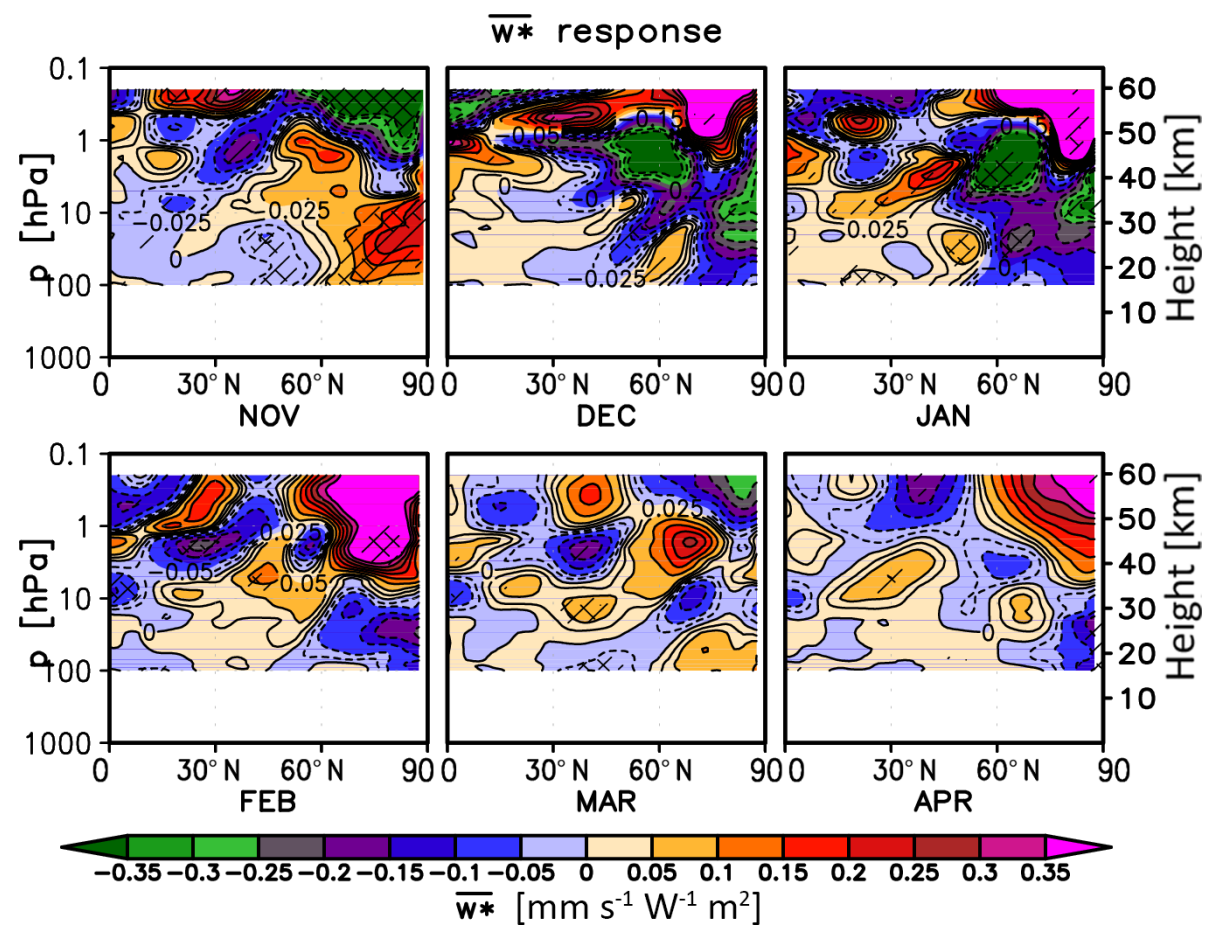

Figure 9. As in Fig. 8 but for the transformed vertical component of the residual circulation ( $\bar{w}^{*}$; see Andrews et al., 1987) response $\left(\mathrm{mm} \mathrm{s}^{-1} \mathrm{~W}^{-1} \mathrm{~m}^{2}\right)$ in UM-UKCA. Positive values indicate upwelling. Note the additional contours at $\pm 0.025 \mathrm{~mm} \mathrm{~s}^{-1} \mathrm{~W}^{-1} \mathrm{~m}^{2}$.

the mid-latitudes, possibly indicating a relative shift in the downwelling region towards the extratropics. In December and January, the sign of the model responses reverses

Thus, the UM-UKCA-simulated changes in planetary wave breaking and $\bar{w}^{*}$ in the high-latitude stratosphere agree with the postulated mechanism (Kuroda and Kodera, 2002; Kodera and Kuroda, 2002), albeit with some differences in the timing of the responses, as well as with the modelling results of Matthes et al. (2004) and Chiodo et al. (2012). Regarding the tropical lower stratosphere, while some indications of solar-cycle-induced upwelling and temperature anomalies that are consistent in terms of a sign with the BDC changes in the Arctic region are found, the magnitudes of the UM-UKCA tropical upwelling (and temperature) anomalies are very small in the lower stratosphere and not strongly statistically significant, indicating that the mechanism is not robustly reproduced in the model.

\section{The role of detection method: composites vs. MLR}

Here we compare the UM-UKCA responses diagnosed by the composite and MLR methods. Model- and reanalysisbased studies in the published literature have adopted both of these methods but they are rarely applied together. The application of both methods to the same model simulations enables a clean comparison of the diagnosed responses.

\subsection{Ensemble yearly mean temperature and zonal wind response}

A comparison between the UM-UKCA tropical temperature responses derived using composites and MLR shows a good agreement between the magnitudes of the detected upper stratospheric/lower mesospheric temperature responses (Fig. 3). However, unlike the weak positive MLR temperature response in the tropical lower stratosphere, composites yield a small statistically insignificant cooling of up to $0.2-$ $0.3 \mathrm{~K} \mathrm{~W}^{-1} \mathrm{~m}^{2}$ in that region. This is likely to be a manifestation of contributions from other forcings that affect lower stratospheric temperatures (e.g. QBO, ENSO) and interannual variability. Interestingly, in the troposphere, while no significant temperature response was detected with MLR in the tropics, composites yield a small, albeit locally statistically significant,warming of up to $\sim 0.2 \mathrm{~K} \mathrm{~W}^{-1} \mathrm{~m}^{2}$. A large part of this temperature dipole structure seen in composites in the tropical troposphere/lower stratosphere is attributed to the residual term in our MLR analysis, with smaller contributions from the influence of ENSO and QBO (see Sect. S1 and Fig. S3).

Similarly, while the composite and MLR zonal wind responses agree, within the uncertainty estimates, in the extratropical stratosphere, some apparent differences were found in the tropical stratosphere and in the troposphere (Fig. 4). Near the equator, there is a strong contribution from the QBO to the composite response, which is better separated 
from the solar component in the MLR analysis (Sect. S1 and Fig. S4). In the troposphere, the UM-UKCA composites suggest an equatorward shift of the SH subtropical jet and a weakening of the polar night jet extending down to the surface at $\sim 60^{\circ} \mathrm{S}$, in qualitative agreement with ERAI (MLR). In contrast, no significant tropospheric response in the SH was found in UM-UKCA using MLR analysis. As with the tropospheric temperature response, the apparent discrepancy between the MLR and composite responses in the troposphere is related to the fact that parts of the latter are attributed to the residual and, to a smaller extent, ENSO terms in the MLR model (Sect. S1 and Fig. S4).

Assuming that the individual forcings are indeed completely independent from each other and linear, the results suggest that MLR achieves a better level of separation of contributions from other processes and interannual variability not directly related to the solar forcing, therefore minimising the effects of aliasing and noise. However, the impacts of individual forcings may not necessarily be independent from one another and additive. A number of studies suggested that coupling of the solar cycle forcing with, for example, QBO and/or ENSO could be important (e.g. Salby and Callaghan, 2000; Pascoe et al., 2005; Labitzke et al., 2006; Haigh and Roscoe, 2006, 2009; Roscoe and Haigh, 2007; Camp and Tung, 2007; Kuroda, 2007; Lu et al., 2009; Calvo and Marsh, 2011; Roy and Haigh, 2011; Matthes et al., 2013). Therefore, we refrain here from judging unambiguously which technique performs better in the detection of the solar responses. More importantly, we stress that the differences between the composite and MLR responses found in the troposphere and in the tropical lower stratosphere, although not statistically significant, illustrate that the use of only one of these techniques could lead to somewhat different conclusions with regard to the solar cycle response and, therefore, highlight that care needs to be taken when analysing solar responses in this region.

\subsection{Ensemble yearly mean ozone response}

Regarding the yearly mean ozone responses in the full ensemble, we find that the total column ozone responses derived in various regions are somewhat higher for MLR than for composites but agree to within the estimated uncertainty ranges (Table 2). Similarly, the spatial patterns of the MLR and composite ozone responses generally agree with each other in a large part of the stratosphere. The main differences (albeit still not statistically significant) occur in the tropical stratosphere. In the lower stratosphere, in contrast to the weak positive MLR response, the composites suggest an ozone decrease of up to $\sim 3 \% \mathrm{~W}^{-1} \mathrm{~m}^{2}-3.5 \% \mathrm{~W}^{-1} \mathrm{~m}^{2}$, consistent with the small temperature decrease found in that region (Fig. 4). As with the temperature and zonal winds, aliasing with other natural forcings could contribute to the tropical lower stratospheric ozone changes diagnosed in the composites, as suggested by the studies of for example Lee and Smith (2003), Marsh and Garcia (2007), Smith and Matthes (2008), and Mitchell et al. (2015b).

\subsection{Ensemble NH seasonal response}

In general, the monthly mean $\mathrm{NH}$ high-latitude temperature and zonal wind responses in UM-UKCA derived using composites and MLR during winter and spring are found to be qualitatively and quantitatively similar within the associated uncertainties (Figs. 6 and 7), with somewhat stronger and more significant strengthening of the tropospheric zonal wind at $\sim 60^{\circ} \mathrm{N}$ found from composites in November.

\section{Solar cycle response over the recent past in the individual ensemble members}

Uncertainties exist regarding the atmospheric response to the 11-year solar cycle forcing. So far, we have focused on the solar cycle response in UM-UKCA across all three ensemble members for the recent past combined. However, observational and reanalysis records such as ERAI or SAGE II represent only a single realisation of the real atmosphere. In order to gain knowledge about underlying variability and, therefore, understand potential issues in deriving solar responses from records comparable in length to the current observations and reanalysis dataset, it is informative to examine the solar responses simulated in each individual ensemble member separately.

The annual mean temperature and ozone responses derived using MLR for the individual ensemble members (denoted ENS1, ENS2 and ENS3) are shown in Figs. 10 and 11, respectively. A reasonable, albeit not perfect, degree of agreement exists between the individual members regarding the tropical mean anomalies: the estimated lower mesospheric temperature maxima range between $\sim 0.7$ and $0.85 \mathrm{~K} \mathrm{~W}^{-1} \mathrm{~m}^{2}$ (Fig. 10d) and the mid-stratospheric ozone maxima between $\sim 2 \% \mathrm{~W}^{-1} \mathrm{~m}^{2}$ and $3 \% \mathrm{~W}^{-1} \mathrm{~m}^{2}$ (Fig. 11d). In both cases, this intra-ensemble spread lies within the associated statistical confidence intervals. Yet, the small differences in the vertical profiles illustrate that natural variability cannot be entirely neglected. In the tropical lower stratosphere, while all three ozone responses are characterised by a broad uncertainty range and individually are not statistically significant, we find both a member which shows no suggestion of a secondary ozone maximum in the region (ENS1) and another one (ENS2) that shows an ozone increase of $\sim 3 \% \mathrm{~W}^{-1} \mathrm{~m}^{2}$ that broadly resembles a secondary tropical ozone maximum similar to that found in observational datasets.

The apparent discrepancy between the ensemble members in the diagnosed annual mean responses is largest in the high latitudes, in case of the temperatures particularly in the NH. This mainly reflects the spread of the anomalies derived during the dynamically active season (see below). Interest- 

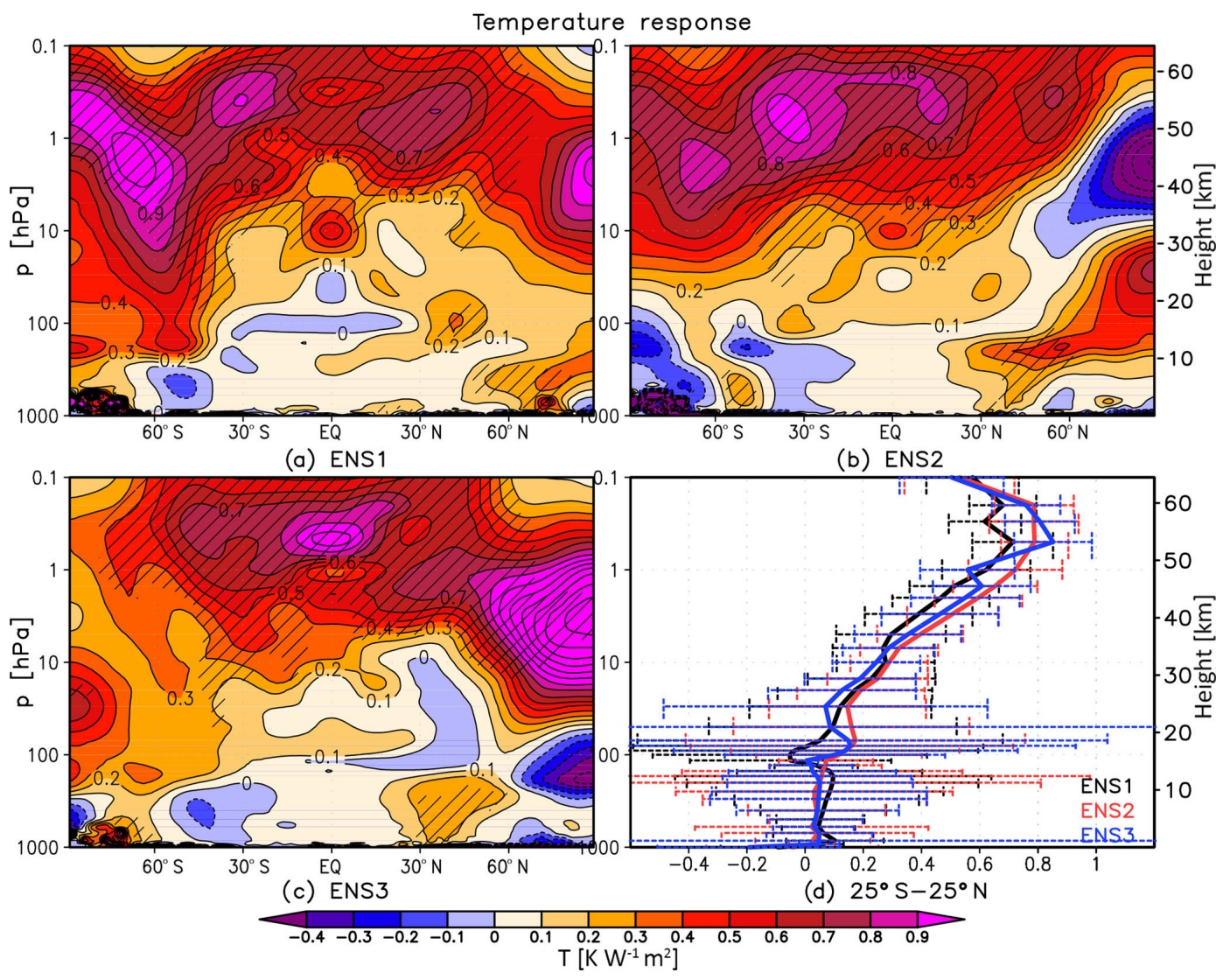

Figure 10. (a-c) Yearly mean zonal mean temperature response $\left(\mathrm{KW}^{-1} \mathrm{~m}^{2}\right)$ in UM-UKCA derived using MLR for the individual ensemble members (ENS1-3). Hatching indicates statistical significance on the $95 \%$ level $\left(t\right.$ test). Contour spacing is $0.1 \mathrm{KW}^{-1} \mathrm{~m}^{2}$. (d) The corresponding yearly mean temperature responses in the tropics together with the associated confidence intervals ( \pm 2 standard errors).

ingly, one member (ENS3) shows an annual mean stratospheric temperature response whose main features resemble the ERAI reanalysis (Fig. 3c). These include the stratopause maximum clearly peaking near the equator (albeit higher up than in ERAI), a strong warming in excess of $1 \mathrm{~K} \mathrm{~W}^{-1} \mathrm{~m}^{2}$ over the $\mathrm{NH}$ polar mid-stratosphere and a suggestion of another temperature maximum in the SH polar stratosphere below $10 \mathrm{hPa}$. Unlike in ERAI, however, a strong secondary temperature maximum in the tropical lower stratosphere is not reproduced in ENS3.

As discussed in Sect. 4, a strengthening of the NH polar vortex (up to $\sim 7 \mathrm{~m} \mathrm{~s}^{-1} \mathrm{~W}^{-1} \mathrm{~m}^{2}$ ) in autumn (November) was diagnosed from the MLR analysis across the full ensemble (Fig. 7). When the integrations are analysed separately, the underlying variability is high from November throughout the rest of the dynamically active season and, consequently, many of the anomalies found in the single ensemble members are not found to be highly statistically significant (Figs. 12 and S5). In November (Fig. 12), only two out of the three ensemble members show the westerly zonal wind anomaly that was found when analysing the full ensemble. Moreover, even for these two members, the magnitudes of the derived responses differ considerably (although not statistically significantly), with the ensemble member ENS2 showing a response of up to $\sim 16 \mathrm{~m} \mathrm{~s}^{-1} \mathrm{~W}^{-1} \mathrm{~m}^{2}$ and ENS3 a smaller response of $\sim 8 \mathrm{~m} \mathrm{~s}^{-1} \mathrm{~W}^{-1} \mathrm{~m}^{2}$. In midwinter (January and February), all members suggest a strengthening of the zonal wind in the extratropical upper stratosphere and lower mesosphere and a weakening in the high latitudes, in qualitative agreement with the response in the full ensemble. Again, the magnitudes of these anomalies differ between the members, although they agree within the estimated uncertainty ranges. In comparison, ERAI shows a strong and fairly robust reversal of the high-latitude zonal wind response in February, with a strong easterly anomaly commonly found in that region (Fig. 7, as well as Matthes et al., 2004; Frame and Gray, 2010; Hood et al., 2015; Mitchell et al., 2015b; Kodera et al., 2016). As illustrated in Fig. 12, while one of our ensemble members (ENS2) shows a statistically significant easterly response of $\sim 18 \mathrm{~m} \mathrm{~s}^{-1} \mathrm{~W}^{-1} \mathrm{~m}^{2}$ in that month, the analogous easterly anomalies found in the remaining two members are comparatively small and not statistically significant. The intra-ensemble agreement somewhat improves in late winter and early spring, with all members indicating a poleward and downward propagation of the westerly re- 

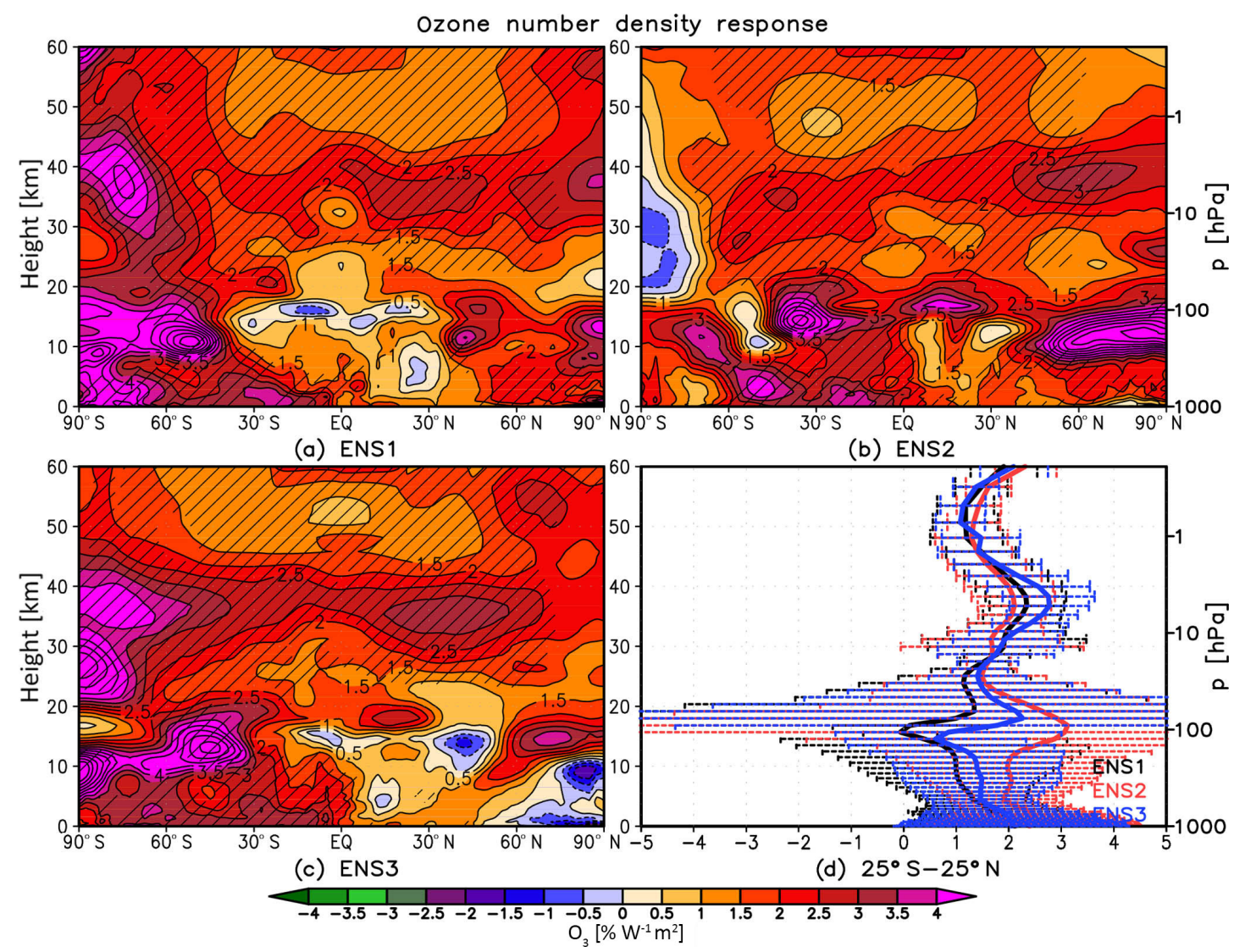

Figure 11. As in Fig. 10 but for the ozone number density response $\left(\% \mathrm{~W}^{-1} \mathrm{~m}^{2}\right)$. Contour spacing is $0.5 \% \mathrm{~W}^{-1} \mathrm{~m}^{2}$ up to $\pm 7 \% \mathrm{~W}^{-1} \mathrm{~m}^{2}$.

sponse in March, followed by an easterly response in April (Fig. S5).

Possibly, the solar cycle signal in the UM-UKCA model is smaller than in the real world, owing to for example the relatively weak SSI forcing (Sects. 3 and 4). The model integrations also show higher interannual variability (i.e. standard deviation) of the $\mathrm{NH}$ zonal wind in parts of the stratosphere, e.g. the upper stratosphere around $60^{\circ} \mathrm{N}$ in autumn and winter, than ERAI (not shown). Both of these effects will impact on the signal-to-noise ratio and the detectability of the solar cycle signal (Scaife and Smith, 2018). Nevertheless, apparent discrepancies between solar responses derived from individual ensemble members have also been noted in other studies (e.g. Austin et al., 2008; Chiodo et al., 2012). Interestingly, Hood et al. (2013) analysed the sea level pressure responses to the solar cycle forcing simulated in the North Pacific and found that limiting the length of their otherwise 16-solarcycle-long simulations to $\sim 9.5$-cycle-long sub-periods can give responses that are apparently stronger and more significant in some of the sub-periods than in the full simulation (or in the other sub-periods).

It is well known that the NH high-latitude winter stratosphere exhibits substantial interannual variability and is influenced by a range of processes and forcings. On the one hand, the relatively long period of the solar cycle can lead to the derived anomalies being affected by aliasing with other atmospheric forcings and processes and/or noise due to interannual variability. From a modelling perspective, it is therefore crucial that the impact of the solar cycle forcing on climate is studied with sufficiently long simulations.

On the other hand, some other atmospheric forcings and processes (e.g. QBO, ENSO) might influence how the solarcycle-induced anomalies develop and propagate through the stratosphere, e.g. by changing the background state and affecting wave propagation. In addition, the solar cycle forcing itself might influence various atmospheric forcings and processes. Indications of such non-linear interactions have been found in observations and/or models (e.g. Salby and Callaghan, 2000; Gray et al., 2004; Pascoe et al., 2005; Labitzke et al., 2006; Haigh and Roscoe, 2006, 2009; Roscoe and Haigh, 2007; Camp and Tung, 2007; Kuroda, 2007; Lu et al., 2009; Calvo and Marsh; 2011, Roy and Haigh, 2011; Matthes et al., 2013). However, given the relatively short length of the satellite record there are still large uncertainties surrounding the derived relationships (e.g. Anstey and Shepherd, 2014). Clearly, in the case of both observational and modelling studies, analysing such a complex and coupled system using linear techniques, like MLR, could potentially lead to spurious 


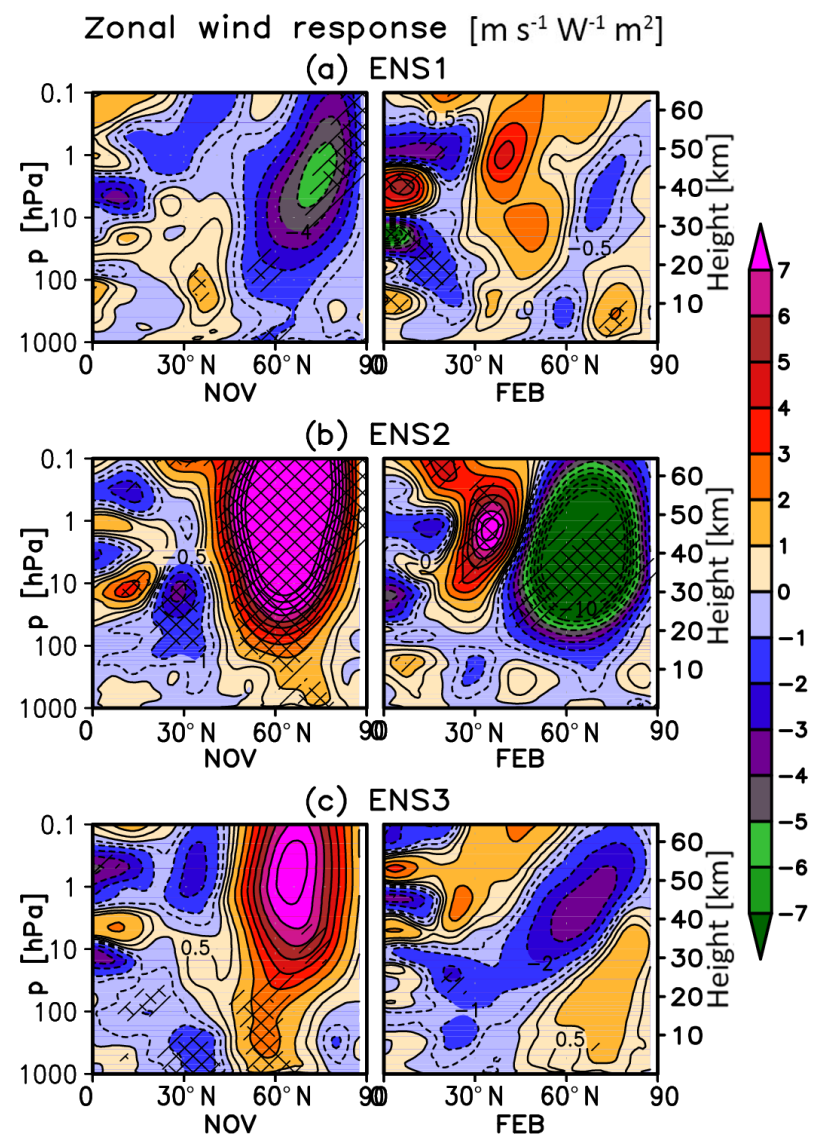

Figure 12. Monthly mean November (left) and February (right) zonal mean zonal wind response $\left(\mathrm{m} \mathrm{s}^{-1} \mathrm{~W}^{-1} \mathrm{~m}^{2}\right)$ in UM-UKCA derived using MLR for the individual ensemble members (ENS13). Single and double hatching indicates statistical significance on the $90 \%$ and $95 \%$ level ( $t$ test). Note the additional contours at $\pm 0.5, \pm 8, \pm 9$ and $\pm 10 \mathrm{~m} \mathrm{~s}^{-1} \mathrm{~W}^{-1} \mathrm{~m}^{2}$. See Fig. S5 for all months from November to April.

signals upon attempting to decouple individual forcings. Our UM-UKCA results thus suggest the need to focus on not just the solar forcing on its own but also on improving our understanding of the underpinning relationships between the solar cycle and other atmospheric forcings and processes, together with the associated mechanisms.

Lastly, recall that a yearly mean tropospheric warming (up to $\sim 0.1-0.2 \mathrm{~K} \mathrm{~W}^{-1} \mathrm{~m}^{2}$ ) resembling that in the reanalysis was derived in the NH mid-latitudes from the full ensemble (Sect. 3.2). We suggested that the UM-UKCA anomaly is influenced by the solar cycle signal present in the prescribed observed SSTs and sea ice, as found to be important in Misios and Schmidt (2013). However, despite the identical SSTs and sea ice only two members (ENS2 and ENS3) show this mid-latitude tropospheric warming, while the remaining member (ENS1) shows a warming over the polar region instead. As seen above, there are apparent differences in the wintertime $\mathrm{NH}$ high-latitude dynamical responses between the individual ensemble members, which are likely to be at least in part caused by the large interannual variability in the region. The results thus suggest that whilst the influence of SSTs and sea ice appears to enhance the NH mid-latitude tropospheric responses to the solar forcing in models, contributions from the variability in the stratosphere (whether or not solar-cycle-induced) and SSTs and sea ice are important for driving the responses in the troposphere (in agreement with, e.g. Rind et al., 2008; Meehl et al., 2009; Gray et al., 2016). Given that any set of prescribed SSTs and sea ice does not necessarily have to be fully consistent with the simulated evolution of the atmosphere, the results indicate the need for coupled atmosphere-ocean models for more confident attribution of tropospheric anomalies to the solar cycle forcing.

\section{Summary}

The 11-year solar cycle is recognised as an important forcing of the climate system. However, there are large uncertainties regarding the signal of solar variability in the atmosphere, which is partly related to uncertainties in the observed response (e.g. Mitchell et al., 2015b; Maycock et al., 2016) as well as marked spread in model-simulated responses (e.g. SPARC CCMVal, 2010; Mitchell et al., 2015a). In this paper, we have presented the first detailed assessment of the atmospheric response to the 11-year solar cycle forcing simulated in the UM-UKCA chemistry-climate model. In contrast to many previous solar cycle studies in the literature, which show solar responses derived using either composite or MLR methodologies, we pay particular attention to the role of detection method by presenting and comparing the results derived using both techniques. In addition, we recognise that interannual variability in the stratosphere can be high, and we examine the impact of the internal atmospheric variability on the derived solar response in UM-UKCA by considering not only the response found from the full three-member ensemble of 1966-2010 integrations but also the spread of responses found from the individual ensemble members.

Regarding the ensemble mean UM-UKCA response, the enhanced solar cycle activity increases the stratospheric shortwave heating rates and temperatures. The resulting yearly mean warming maximises near the tropical stratopause at $\sim 0.8 \mathrm{~K} \mathrm{~W}^{-1} \mathrm{~m}^{2}$. The response occurs at higher altitudes and is $\sim 25 \%$ smaller than that derived from ERAI. A number of factors possibly contributing to this underestimation of model temperature response were identified (Sect. 3.2.1): (i) the relatively broadband shortwave heating scheme, (ii) the lack of $\mathrm{O}_{2} \mathrm{UV}$ absorption in the radiation scheme, (iii) the underestimation $(\sim 20 \%)$ of UV $(200-320 \mathrm{~nm})$ variability in the radiation scheme compared with CMIP5, (iv) the use of a modest SSI variability (Ermolli et al., 2013) and (v) uncertainties in the reanalysis (Mitchell et al., 2015b). For ozone, the UM-UKCA model simulates a yearly mean tropical ozone increase of up 
to $\sim 2.0-2.5 \% \mathrm{~W}^{-1} \mathrm{~m}^{2}$ in the mid-stratosphere. Unlike the more peaked and locally stronger SAGE II ozone response, the maximum model response is weaker, more horizontally uniform and occurs at lower altitudes. We note that differences exist between the temperature and ozone responses derived from various observational and reanalysis datasets (Soukharev and Hood, 2006; Dhomse et al., 2013, 2016; Mitchell et al., 2015b; Maycock et al., 2016, 2018). Averaged over the globe, the yearly mean total ozone column response simulated in UM-UKCA was estimated (MLR) to be of $\sim 6 \mathrm{DUW}^{-1} \mathrm{~m}^{2}$.

The analysis did not find a yearly mean secondary temperature or ozone maximum in the model in the tropical lower stratosphere as seen in the reanalysis. This may be related to differences in the associated dynamical responses in both hemispheres, as manifested by the absence in the model of the yearly mean strengthening of the extratropical stratospheric jets seen in ERAI. Despite that, we do find a small warming of up to $\sim 0.1-0.2 \mathrm{KW}^{-1} \mathrm{~m}^{2}$ in the $\mathrm{NH}$ mid-latitude troposphere alongside the associated weakening of the NH subtropical jet on its equatorial side. This tropospheric/lower stratospheric response is in broad qualitative agreement with the reanalysis and suggests a contribution of the solar signal in the prescribed SSTs and sea ice, as found by Misios and Schmidt (2013).

In accord with the mechanism postulated by Kuroda and Kodera (2002) and Kodera and Kuroda (2002), the enhancement of the horizontal temperature gradient under increased solar cycle activity strengthens and cools the NH stratospheric vortex in autumn. The simulated response extends to the troposphere in November. A sign reversal of the modelled stratospheric response occurs in midwinter (January). The modulation of the NH polar jet in the model is associated with consistent changes in planetary wave propagation and, at least in the high latitudes, the meridional overturning circulation. In general, the evolution of the $\mathrm{NH}$ dynamical solar response in UM-UKCA during autumn and winter shows some broad resemblance to that seen in ERAI. However, the model shows earlier timing of the responses, which could be related to the positive bias in the model's zonal wind climatology and/or SSI forcing that is too weak. In addition to the different timing, the simulated westerly response diagnosed from monthly mean data appears at higher latitudes than in ERAI, thereby not clearly reproducing the poleward and downward propagation. In general, any (monthly mean) westerly anomalies near the subtropical stratopause in UMUKCA are much weaker and shorter-lived than in ERAI; the UM-UKCA model ensemble also does not reproduce the westerly anomaly observed in the NH mid- to high latitudes in mid- and late spring (April onwards).

Regarding the role of detection method for the derived solar response, we find that the stratospheric solar responses diagnosed using both the composite and MLR methodologies are, within the associated uncertainty, generally in agreement with each other. Some apparent differences (although mostly not highly statistically significant) are found in the troposphere and in the tropical lower stratosphere. Depending on whether the individual forcings are indeed independent from each other and linear, these could arise either due to noise from the natural/interannual variability and/or aliasing between the solar and other atmospheric forcings, or they could in principle be a manifestation of some non-linear interactions between the solar and other atmospheric forcings and processes. The results highlight that care needs to be taken when investigating the role of the solar cycle forcing in these regions as using only one of the techniques could lead to somewhat different conclusions with regard to the atmospheric impacts of the 11-year solar cycle.

Lastly, in order to understand potential issues in deriving atmospheric responses to the solar cycle forcing from records comparable in length to the current observational and reanalysis datasets, we discuss the model results derived from the individual ensemble members. We find that the yearly mean tropical temperature and ozone responses derived from the individual integrations in the mid-/upper stratosphere and lower mesosphere are in fair agreement with each other (within the uncertainty) as well as with the response derived from the full ensemble. However, there are larger apparent differences between the individual members in the NH high latitudes; these are mainly related to the apparent differences simulated during the dynamically active season. The spread of the diagnosed NH responses is particularly large in late autumn and early winter and gradually lessens later in the season. This suggest that the solar anomalies detected in the highly variable NH high latitudes could be influenced by noise and/or aliasing due to large variability in the region. In addition, non-linear interactions between the solar and other atmospheric forcings and processes might also play a role over shorter timescales. The UM-UKCA results suggest the need for long time series for confident detection of solar anomalies as well as for more research on understanding the relationships between the solar cycle forcing and other atmospheric forcings and processes. Finally, we find that the yearly mean tropospheric warming detected in the NH mid-latitudes from the full ensemble is only reproduced in two out of three ensemble members. This suggests that while the SSTs and sea-ice forcing appears to be an important contributor to the modelled tropospheric responses (Misios and Schmidt, 2013), contributions from both stratospheric variability and SSTs and sea ice are important for driving the modelled anomalies (see also Rind et al., 2008; Meehl et al., 2009; Gray et al., 2016). The results indicate the need to use coupled atmosphere-ocean models in order to fully capture the impacts of the solar cycle forcing on the tropospheric climate.

Data availability. ERAI data are available at https://www.ecmwf. int/en/forecasts/datasets/reanalysis-datasets/era-interim (last access: 4 April 2019); SAGE II data are available at https://eosweb. 
larc.nasa.gov/project/sage2/sage2_table (last access: 4 April 2019); model output is available on request.

Supplement. The supplement related to this article is available online at: https://doi.org/10.5194/acp-19-5209-2019-supplement.

Author contributions. EMB ran the model experiments, analysed the data and wrote the paper, with discussion, feedback and input from ACM, PB and JAP. NLA prepared the model version and the experimental set-up and forcings; PJT implemented the solar cycle variability into UM-UKCA.

Competing interests. The authors declare that they have no conflict of interest.

Acknowledgements. Amanda C. Maycock, John A. Pyle, Paul J. Telford and N. Luke Abraham were supported by the National Centre for Atmospheric Science, a NERC-funded research centre. We acknowledge funding from the ERC for the ACCI project grant number 267760, including PhD studentship for Ewa M. Bednarz. ACM acknowledges support from an AXA Postdoctoral Fellowship and NERC Independent Research Fellowship (grant NE/M018199/1).

We acknowledge the use of HECToR, the UK's national high-performance computing service. We thank Markus Kunze for providing the MLR software (including the EESC forcing). The authors also thank Fiona O'Connor and Katja Matthes for providing the relevant solar cycle forcing data and/or model code needed for model development, as well as the two anonymous referees for their constructive comments.

Edited by: Martin Dameris

Reviewed by: two anonymous referees

\section{References}

Andrews, D. G., Holton, J. R., and Leovy, C. B.: Middle Atmosphere Dynamics, Academic Press, San Diego, 489 pp., 1987.

Anstey, J. A. and Shepherd, T. G..: High-latitude influence of the quasi-biennial oscillation, Q. J. Roy. Meteor. Soc., 140, 1-21, https://doi.org/10.1002/qj.2132, 2014.

Austin, J., Hood, L. L., and Soukharev, B. E.: Solar cycle variations of stratospheric ozone and temperature in simulations of a coupled chemistry-climate model, Atmos. Chem. Phys., 7, 16931706, https://doi.org/10.5194/acp-7-1693-2007, 2007.

Austin, J., Tourpali, K., Rozanov, E., Akiyoshi, H., Bekki, S., Bodeker, G., Bruhl, C., Butchart, N., Chipperfield, M., Deushi, M., Fomichev, V. I., Giorgetta, M. A., Gray, L., Kodera, K., Lott, F., Manzini, E., Marsh, D., Matthes, K., Nagashima, T., Shibata, K., Stolarski, R. S., Struthers, H., and Tian, W.: Coupled chemistry climate model simulations of the solar cycle in ozone and temperature, J. Geophys. Res.-Atmos., 113, D11306, https://doi.org/10.1029/2007jd009391, 2008.
Bednarz, E. M., Maycock, A. C., Abraham, N. L., Braesicke, P., Dessens, O., and Pyle, J. A.: Future Arctic ozone recovery: the importance of chemistry and dynamics, Atmos. Chem. Phys., 16, 12159-12176, https://doi.org/10.5194/acp-16-121592016, 2016.

Bednarz, E. M., Maycock, A. C., Braesicke, P., Telford, P. J., Abraham, N. L., and Pyle, J. A.: Separating the role of direct radiative heating and photolysis in modulating the atmospheric response to the 11 year solar cycle forcing, Atmos. Chem. Phys. Discuss., https://doi.org/10.5194/acp-2018-321, in review, 2018.

Bednarz, E. M., Maycock, A. C., Braesicke, P., Telford, P. J., Abraham, N. L., and Pyle, J. A.: The role of solar-ozone feedback in modulating the atmospheric response to the 11 year solar cycle, in prep., 2019.

Bodeker, G. E., Boyd, I. S., and Matthews, W. A.: Trends and variability in vertical ozone and temperature profiles measured by ozonesondes at Lauder, New Zealand: 1986-1996, J. Geophys. Res.-Atmos., 103, 28661-28681, https://doi.org/10.1029/98jd02581, 1998.

Calvo, N. and Marsh, D. R.: The combined effects of ENSO and the 11 year solar cycle on the Northern Hemisphere polar stratosphere, J. Geophys. Res.-Atmos., 116, D23112, https://doi.org/10.1029/2010jd015226, 2011.

Camp, C. D. and Tung, K. K.: The influence of the solar cycle and $\mathrm{QBO}$ on the late-winter stratospheric polar vortex, J. Atmos. Sci., 64, 1267-1283, https://doi.org/10.1175/jas3883.1, 2007.

Charney, J. G. and Drazin, P. G.: Propagation of planetary-scale disturbances from lower into upper atmosphere, J. Geophys. Res., 66, 83-109, https://doi.org/10.1029/JZ066i001p00083, 1961.

Chiodo, G., Calvo, N., Marsh, D. R., and Garcia-Herrera, R.: The 11 year solar cycle signal in transient simulations from the Whole Atmosphere Community Climate Model, J. Geophys. Res.Atmos., 117, D06109, https://doi.org/10.1029/2011jd016393, 2012.

Chiodo, G., Marsh, D. R., Garcia-Herrera, R., Calvo, N., and García, J. A.: On the detection of the solar signal in the tropical stratosphere, Atmos. Chem. Phys., 14, 5251-5269, https://doi.org/10.5194/acp-14-5251-2014, 2014.

Chipperfield, M. P., Liang, Q., Strahan, S. E., Morgenstern, O., Dhomse, S. S., Abraham, N. L., Archibald, A. T., Bekki, S., Braesicke, P., Di Genova, G., Fleming, E. L., Hardiman, S. C., Iachetti, D., Jackman, C. H., Kinnison, D. E., Marchand, M., Pitari, G., Pyle, J. A., Rozanov, E., Stenke, A., and Tummon, F.: Multimodel estimates of atmospheric lifetimes of long-lived ozonedepleting substances: Present and future, J. Geophys. Res.Atmos., 119, 2555-2573, https://doi.org/10.1002/2013jd021097, 2014.

Damadeo, R. P., Zawodny, J. M., Thomason, L. W., and Iyer, N.: SAGE version 7.0 algorithm: application to SAGE II, Atmos. Meas. Tech., 6, 3539-3561, https://doi.org/10.5194/amt-6-35392013, 2013.

Damadeo, R. P., Zawodny, J. M., and Thomason, L. W.: Reevaluation of stratospheric ozone trends from SAGE II data using a simultaneous temporal and spatial analysis, Atmos. Chem. Phys., 14, 13455-13470, https://doi.org/10.5194/acp-14-134552014, 2014.

Davies, T., Cullen, M. J. P., Malcolm, A. J., Mawson, M. H., Staniforth, A., White, A. A., and Wood, N.: A new dynamical core for the Met Office's global and regional modelling 
of the atmosphere, Q. J. Roy. Meteor. Soc., 131, 1759-1782, https://doi.org/10.1256/qj.04.101, 2005.

Dee, D. P., Uppala, S. M., Simmons, A. J., Berrisford, P., Poli, P., Kobayashi, S., Andrae, U., Balmaseda, M. A., Balsamo, G., Bauer, P., Bechtold, P., Beljaars, A. C. M., van de Berg, L., Bidlot, J., Bormann, N., Delsol, C., Dragani, R., Fuentes, M., Geer, A. J., Haimberger, L., Healy, S. B., Hersbach, H., Holm, E. V., Isaksen, L., Kallberg, P., Kohler, M., Matricardi, M., McNally, A. P., Monge-Sanz, B. M., Morcrette, J. J., Park, B. K., Peubey, C., de Rosnay, P., Tavolato, C., Thepaut, J. N., and Vitart, F.: The ERA-Interim reanalysis: configuration and performance of the data assimilation system, Q. J. Roy. Meteor. Soc., 137, 553-597, https://doi.org/10.1002/qj.828, 2011.

Dhomse, S. S., Chipperfield, M. P., Feng, W., Ball, W. T., Unruh, Y. C., Haigh, J. D., Krivova, N. A., Solanki, S. K., and Smith, A. K.: Stratospheric $\mathrm{O}_{3}$ changes during 2001-2010: the small role of solar flux variations in a chemical transport model, Atmos. Chem. Phys., 13, 10113-10123, https://doi.org/10.5194/acp-1310113-2013, 2013.

Dhomse, S. S., Chipperfield, M. P., Damadeo, R. P., Zawodny, J. M., Ball, W. T., Feng, W., Hossaini, R., Mann, G. W., and Haigh, J. D.: On the ambiguous nature of the 11 year solar cycle signal in upper stratospheric ozone, Geophys. Res. Lett., 43, 7241-7249, https://doi.org/10.1002/2016GL069958, 2016.

Dunkerton, T. J., Delisi, D. P., and Baldwin, M. P.: Middle atmosphere cooling trend in historical rocketsonde data, Geophys. Res. Lett., 25, 3371-3374, https://doi.org/10.1029/98g102385, 1998.

Edwards, J. M. and Slingo, A.: Studies with a flexible new radiation code. 1. Choosing a configuration for a largescale model, Q. J. Roy. Meteor. Soc., 122, 689-719, https://doi.org/10.1256/smsqj.53106, 1996.

Ermolli, I., Matthes, K., Dudok de Wit, T., Krivova, N. A., Tourpali, K., Weber, M., Unruh, Y. C., Gray, L., Langematz, U., Pilewskie, P., Rozanov, E., Schmutz, W., Shapiro, A., Solanki, S. K., and Woods, T. N.: Recent variability of the solar spectral irradiance and its impact on climate modelling, Atmos. Chem. Phys., 13, 3945-3977, https://doi.org/10.5194/acp-13-3945-2013, 2013.

Eyring, V., Waugh, D. W., Bodeker, G. E., Cordero, E., Akiyoshi, H., Austin, J., Beagley, S. R., Boville, B. A., Braesicke, P., Bruhl, C., Butchart, N., Chipperfield, M. P., Dameris, M., Deckert, R., Deushi, M., Frith, S. M., Garcia, R. R., Gettelman, A., Giorgetta, M. A., Kinnison, D. E., Mancini, E., Manzini, E., Marsh, D. R., Matthes, S., Nagashima, T., Newman, P. A., Nielsen, J. E., Pawson, S., Pitari, G., Plummer, D. A., Rozanov, E., Schraner, M., Scinocca, J. F., Semeniuk, K., Shepherd, T. G., Shibata, K., Steil, B., Stolarski, R. S., Tian, W., and Yoshiki, M.: Multimodel projections of stratospheric ozone in the 21 st century, J. Geophys. Res.-Atmos., 112, D16303, https://doi.org/10.1029/2006jd008332, 2007.

Eyring, V., Chipperfield, M. P., Giorgetta, M. A., Kinnison, D. E., Manzini, E., Matthes, K., Newman, P. A., Pawson, S., Shepherd, T. G., and Waugh, D. W.: Overview of the New CCMVal Reference and Sensitivity Simulations in Support of Upcoming Ozone and Climate Assessments and the Planned SPARC CCMVal Report, SPARC Newsletter No. 30, 20-26, 2008.

Frame, T. H. A. and Gray, L. J.: The 11-Yr Solar Cycle in ERA-40 Data: An Update to 2008, J. Climate, 23, 2213-2222, https://doi.org/10.1175/2009jcli3150.1, 2010.
Fröhlich, C. and Lean, J.: The Sun's total irradiance: Cycles, trends and related climate change uncertainties since 1976, Geophys. Res. Lett., 25, 4377-4380, https://doi.org/10.1029/1998g1900157, 1998.

Gray, L. J., Rumbold, S. T., and Shine, K. P.: Stratospheric Temperature and Radiative Forcing Response to 11-Year Solar Cycle Changes in Irradiance and Ozone, J. Atmos. Sci., 66, 2402-2417, https://doi.org/10.1175/2009jas2866.1, 2009.

Gray, L. J., Beer, J., Geller, M., Haigh, J. D., Lockwood, M., Matthes, K., Cubasch, U., Fleitmann, D., Harrison, G., Hood, L., Luterbacher, J., Meehl, G. A., Shindell, D., van Geel, B., and White, W.: Solar influences on climate, Rev. Geophys., 48, RG4001, https://doi.org/10.1029/2009rg000282, 2010.

Gray, L. J., Scaife, A. A., Mitchell, D. M., Osprey, S., Ineson, S., Hardiman, S., Butchart, N., Knight, J., Sutton, R., and Kodera, K.: A lagged response to the 11 year solar cycle in observed winter Atlantic/European weather patterns, J. Geophys. Res.-Atmos., 118, 13405-13420, https://doi.org/10.1002/2013jd020062, 2013.

Gray, L. J., Woollings, T. J., Andrews, M., and Knight, J.: Eleven year solar cycle signal in the NAO and Atlantic/European blocking, Q. J. Roy. Meteor. Soc., 142, 18901903, https://doi.org/10.1002/qj.2782, 2016.

Haigh, J. D.: The role of stratospheric ozone in modulating the solar radiative forcing of climate, Nature, 370, 544-546, https://doi.org/10.1038/370544a0, 1994.

Haigh, J. D.: A GCM study of climate change in response to the 11 year solar cycle, Q. J. Roy. Meteor. Soc., 125, 871-892, 1999.

Haigh, J. D.: Solar Variability and the Stratosphere, in: Stratosphere: Dynamics, Transport, and Chemistry, edited by: Polvani, L. M., Sobel, A. H., and Waugh, D. W., Geoph. Monog. Series, American Geophysical Union, Washington, 173-187, https://doi.org/10.1002/9781118666630.ch10, 2010.

Haigh, J. D., Blackburn, M., and Day, R.: The response of tropospheric circulation to perturbations in lowerstratospheric temperature, J. Climate, 18, 3672-3685, https://doi.org/10.1175/jcli3472.1, 2005.

Haigh, J. D. and Blackburn, M.: Solar influences on dynamical coupling between the stratosphere and troposphere, Space Sci. Rev., 125, 331-344, https://doi.org/10.1007/s11214-006-9067-0, 2006.

Haigh, J. D. and Roscoe, H. K.: Solar influences on polar modes of variability, Meteorol. Z., 15, 371-378, https://doi.org/10.1127/0941-2948/2006/0123, 2006.

Haigh, J. D. and Roscoe, H. K.: The Final Warming Date of the Antarctic Polar Vortex and Influences on its Interannual Variability, J. Climate, 22, 5809-5819, https://doi.org/10.1175/2009jcli2865.1, 2009.

Harder, J. W., Fontenla, J. M., Pilewskie, P., Richard, E. C., and Woods, T. N.: Trends in solar spectral irradiance variability in the visible and infrared, Geophys. Res. Lett., 36, L07801, https://doi.org/10.1029/2008gl036797, 2009.

Hewitt, H. T., Copsey, D., Culverwell, I. D., Harris, C. M., Hill, R. S. R., Keen, A. B., McLaren, A. J., and Hunke, E. C.: Design and implementation of the infrastructure of HadGEM3: the next-generation Met Office climate modelling system, Geosci. Model Dev., 4, 223-253, https://doi.org/10.5194/gmd-4-2232011, 2011. 
Hood, L., Schimanke, S., Spangehl, T., Bal, S., and Cubasch, U.: The Surface Climate Response to 11-Yr Solar Forcing during Northern Winter: Observational Analyses and Comparisons with GCM Simulations, J. Climate, 26, 7489-7506, https://doi.org/10.1175/jcli-d-12-00843.1, 2013.

Hood, L. L., Misios, S., Mitchell, D. M., Rozanov, E., Gray, L. J., Tourpali, K., Matthes, K., Schmidt, H., Chiodo, G., Thieblemont, R., Shindell, D., and Krivolutsky, A.: Solar signals in CMIP-5 simulations: the ozone response, Q. J. Roy. Meteor. Soc., 141, 2670-2689, https://doi.org/10.1002/qj.2553, 2015.

IPCC (Intergovernmental Panel on Climate Change): Special Report on Emissions Scenarios, edited by: Nakicenovic, N. and Swart, R., Cambridge University Press, Cambridge, UK, 570 pp., 2000.

Jones, C. D., Hughes, J. K., Bellouin, N., Hardiman, S. C., Jones, G. S., Knight, J., Liddicoat, S., O'Connor, F. M., Andres, R. J., Bell, C., Boo, K.-O., Bozzo, A., Butchart, N., Cadule, P., Corbin, K. D., Doutriaux-Boucher, M., Friedlingstein, P., Gornall, J., Gray, L., Halloran, P. R., Hurtt, G., Ingram, W. J., Lamarque, J.-F., Law, R. M., Meinshausen, M., Osprey, S., Palin, E. J., Parsons Chini, L., Raddatz, T., Sanderson, M. G., Sellar, A. A., Schurer, A., Valdes, P., Wood, N., Woodward, S., Yoshioka, M., and Zerroukat, M.: The HadGEM2-ES implementation of CMIP5 centennial simulations, Geosci. Model Dev., 4, 543-570, https://doi.org/10.5194/gmd-4-543-2011, 2011.

Keckhut, P., Cagnazzo, C., Chanin, M. L., Claud, C., and Hauchecorne, A.: The 11 year solar-cycle effects on the temperature in the upper-stratosphere and mesosphere: Part I - Assessment of observations, J. Atmos. Sol.-Terr. Phy., 67, 940-947, https://doi.org/10.1016/j.jastp.2005.01.008, 2005.

Kodera, K. and Kuroda, Y.: Dynamical response to the solar cycle, J. Geophys. Res.-Atmos., 107, 4749, https://doi.org/10.1029/2002jd002224, 2002.

Kodera, K., Matthes, K., Shibata, K., Langematz, U., and Kuroda, Y.: Solar impact on the lower mesospheric subtropical jet: A comparative study with general circulation model simulations, Geophys. Res. Lett., 30, 1315, https://doi.org/10.1029/2002gl016124, 2003.

Kodera, K., Thiéblemont, R., Yukimoto, S., and Matthes, K.: How can we understand the global distribution of the solar cycle signal on the Earth's surface?, Atmos. Chem. Phys., 16, 12925-12944, https://doi.org/10.5194/acp-16-12925-2016, 2016.

Kunze, M., Braesicke, P., Langematz, U., and Stiller, G.: Interannual variability of the boreal summer tropical UTLS in observations and CCMVal-2 simulations, Atmos. Chem. Phys., 16, 8695-8714, https://doi.org/10.5194/acp-16-8695-2016, 2016.

Kuroda, Y.: Effect of QBO and ENSO on the solar cycle modulation of winter North Atlantic Oscillation, J. Meteorol. Soc. Jpn., 85, 889-898, https://doi.org/10.2151/jmsj.85.889, 2007.

Kuroda, Y. and Kodera, K.: Effect of solar activity on the Polar-night jet oscillation in the northern and southern hemisphere winter, J. Meteorol. Soc. Jpn., 80, 973-984, https://doi.org/10.2151/jmsj.80.973, 2002.

Labitzke, K., Kunze, M., and Bronnimann, S.: Sunspots, the QBO and the stratosphere in the North Polar Region - 20 years later, Meteorol. Z., 15, 355-363, https://doi.org/10.1127/09412948/2006/0136, 2006.
Lary, D. J. and Pyle, J. A.: Diffuse-radiation, twilight, and photochemistry - 1, J. Atmos. Chem., 13, 373-392, https://doi.org/10.1007/bf00057753, 1991.

Lean, J.: Evolution of the sun's spectral irradiance since the Maunder Minimum, Geophys. Res. Lett., 27, 2425-2428, https://doi.org/10.1029/2000gl000043, 2000.

Lean, J.: Calculations of Solar Irradiance: monthly means from 1882 to 2008 , annual means from 1610 to 2008 , available at: http://solarisheppa.geomar.de/solarisheppa/sites/default/ files/data/Calculations_of_Solar_Irradiance.pdf (last access: 13 September 2016), 2009.

Lean, J. L., White, O. R., and Skumanich, A.: On the solar ultraviolet spectral irradiance during the Maunder Minimum, Global Biogeochem. Cy., 9, 171-182, https://doi.org/10.1029/95gb00159, 1995.

Lean, J. L.: Evolution of Total Atmospheric Ozone from 1900 to 2100 Estimated with Statistical Models, J. Atmos. Sci., 71, 1956-1984, https://doi.org/10.1175/jas-d-13-052.1, 2014.

Lee, H. and Smith, A. K.: Simulation of the combined effects of solar cycle, quasi-biennial oscillation, and volcanic forcing on stratospheric ozone changes in recent decades, J. Geophys. Res.Atmos., 108, 4049, https://doi.org/10.1029/2001jd001503, 2003.

Long, C. S., Fujiwara, M., Davis, S., Mitchell, D. M., and Wright, C. J.: Climatology and interannual variability of dynamic variables in multiple reanalyses evaluated by the SPARC Reanalysis Intercomparison Project (S-RIP), Atmos. Chem. Phys., 17, 14593 14629, https://doi.org/10.5194/acp-17-14593-2017, 2017.

Lu, H., Gray, L. J., Baldwin, M. P., and Jarvis, M. J.: Life cycle of the QBO-modulated 11 year solar cycle signals in the Northern Hemispheric winter, Q. J. Roy. Meteor. Soc., 135, 1030-1043, https://doi.org/10.1002/qj.419, 2009.

Marsh, D. R. and Garcia, R. R.: Attribution of decadal variability in lower-stratospheric tropical ozone, Geophys. Res. Lett., 34, L21807, https://doi.org/10.1029/2007g1030935, 2007.

Matthes, K., Langematz, U., Gray, L. L., Kodera, K., and Labitzke, K.: Improved 11 year solar signal in the freie universitat Berlin climate middle atmosphere model (FUB-CMAM), J. Geophys. Res.-Atmos., 109, D06101, https://doi.org/10.1029/2003jd004012, 2004.

Matthes, K., Kuroda, Y., Kodera, K., and Langematz, U., Transfer of the solar signal from the stratosphere to the troposphere: Northern winter, J. Geophys. Res.-Atmos., 111, D06108, https://doi.org/10.1029/2005JD006283, 2006.

Matthes, K., Kodera, K., Garcia, R. R., Kuroda, Y., Marsh, D. R., and Labitzke, K.: The importance of time-varying forcing for QBO modulation of the atmospheric 11 year solar cycle signal, J. Geophys. Res.-Atmos., 118, 4435-4447, https://doi.org/10.1002/jgrd.50424, 2013.

Maycock, A. C., Matthes, K., Tegtmeier, S., Thiéblemont, R., and Hood, L.: The representation of solar cycle signals in stratospheric ozone - Part 1: A comparison of recently updated satellite observations, Atmos. Chem. Phys., 16, 10021-10043, https://doi.org/10.5194/acp-16-10021-2016, 2016.

Maycock, A. C., Matthes, K., Tegtmeier, S., Schmidt, H., Thiéblemont, R., Hood, L., Akiyoshi, H., Bekki, S., Deushi, M., Jöckel, P., Kirner, O., Kunze, M., Marchand, M., Marsh, D. R., Michou, M., Plummer, D., Revell, L. E., Rozanov, E., Stenke, A., Yamashita, Y., and Yoshida, K.: The representation of solar cycle signals in stratospheric ozone - Part 2: Analy- 
sis of global models, Atmos. Chem. Phys., 18, 11323-11343, https://doi.org/10.5194/acp-18-11323-2018, 2018.

McLandress, C., Plummer, D. A., and Shepherd, T. G.: Technical Note: A simple procedure for removing temporal discontinuities in ERA-Interim upper stratospheric temperatures for use in nudged chemistry-climate model simulations, Atmos. Chem. Phys., 14, 1547-1555, https://doi.org/10.5194/acp14-1547-2014, 2014.

Meehl, G. A., Arblaster, J. M., Matthes, K., Sassi, F., and van Loon, H.: Amplifying the Pacific Climate System Response to a Small 11-Year Solar Cycle Forcing, Science, 325, 1114-1118, https://doi.org/10.1126/science.1172872, 2009.

Misios, S. and Schmidt, H.: The role of the oceans in shaping the tropospheric response to the 11 year solar cycle, Geophys. Res. Lett., 40, 6373-6377, https://doi.org/10.1002/2013gl058439, 2013.

Mitchell, D. M., Misios, S., Gray, L. J., Tourpali, K., Matthes, K., Hood, L., Schmidt, H., Chiodo, G., Thieblemont, R., Rozanov, E., Shindell, D., and Krivolutsky, A.: Solar signals in CMIP-5 simulations: the stratospheric pathway, Q. J. Roy. Meteor. Soc., 141, 2390-2403, https://doi.org/10.1002/qj.2530, 2015a.

Mitchell, D. M., Gray, L. J., Fujiwara, M., Hibino, T., Anstey, J. A., Ebisuzaki, W., Harada, Y., Long, C., Misios, S., Stott, P. A., and Tan, D.: Signatures of naturally induced variability in the atmosphere using multiple reanalysis datasets, Q. J. Roy. Meteor. Soc., 141, 2011-2031, https://doi.org/10.1002/qj.2492, 2015 b.

Morgenstern, O., Braesicke, P., O'Connor, F. M., Bushell, A. C., Johnson, C. E., Osprey, S. M., and Pyle, J. A.: Evaluation of the new UKCA climate-composition model Part 1: The stratosphere, Geosci. Model Dev., 2, 43-57, https://doi.org/10.5194/gmd-2-43-2009, 2009.

Morgenstern, O., Giorgetta, M. A., Shibata, K., Eyring, V., Waugh, D. W., Shepherd, T. G., Akiyoshi, H., Austin, J., Baumgaertner, A. J. G., Bekki, S., Braesicke, P., Bruhl, C., Chipperfield, M. P., Cugnet, D., Dameris, M., Dhomse, S., Frith, S. M., Garny, H., Gettelman, A., Hardiman, S. C., Hegglin, M. I., Jockel, P., Kinnison, D. E., Lamarque, J. F., Mancini, E., Manzini, E., Marchand, M., Michou, M., Nakamura, T., Nielsen, J. E., Olivie, D., Pitari, G., Plummer, D. A., Rozanov, E., Scinocca, J. F., Smale, D., Teyssedre, H., Toohey, M., Tian, W., and Yamashita, Y.: Review of the formulation of presentgeneration stratospheric chemistry-climate models and associated external forcings, J. Geophys. Res.-Atmos., 115, D00M02, https://doi.org/10.1029/2009jd013728, 2010.

Newman, P. A., Daniel, J. S., Waugh, D. W., and Nash, E. R.: A new formulation of equivalent effective stratospheric chlorine (EESC), Atmos. Chem. Phys., 7, 4537-4552, https://doi.org/10.5194/acp-7-4537-2007, 2007.

Nissen, K. M., Matthes, K., Langematz, U., and Mayer, B.: Towards a better representation of the solar cycle in general circulation models, Atmos. Chem. Phys., 7, 5391-5400, https://doi.org/10.5194/acp-7-5391-2007, 2007.

Pascoe, C. L., Gray, L. J., Crooks, S. A., Juckes, M. N., and Baldwin, M. P.: The quasi-biennial oscillation: Analysis using ERA-40 data, J. Geophys. Res.-Atmos., 110, D08105, https://doi.org/10.1029/2004jd004941, 2005.

Ramaswamy, V., Chanin, M. L., Angell, J., Barnett, J., Gaffen, D., Gelman, M., Keckhut, P., Koshelkov, Y., Labitzke, K., Lin, J. J. R., O’Neill, A., Nash, J., Randel, W., Rood, R., Shine, K., Sh- iotani, M., and Swinbank, R.: Stratospheric temperature trends: Observations and model simulations, Rev. Geophys., 39, 71-122, https://doi.org/10.1029/1999rg000065, 2001.

Randel, W. J. and Wu, F.: A stratospheric ozone profile data set for 1979-2005: Variability, trends, and comparisons with column ozone data, J. Geophys. Res.-Atmos., 112, D06313, https://doi.org/10.1029/2006jd007339, 2007.

Randel, W. J., Shine, K. P., Austin, J., Barnett, J., Claud, C., Gillett, N. P., Keckhut, P., Langematz, U., Lin, R., Long, C., Mears, C., Miller, A., Nash, J., Seidel, D. J., Thompson, D. W. J., Wu, F., and Yoden, S.: An update of observed stratospheric temperature trends, J. Geophys. Res.-Atmos., 114, D02107, https://doi.org/10.1029/2008jd010421, 2009.

Rayner, N. A., Parker, D. E., Horton, E. B., Folland, C. K., Alexander, L. V., Rowell, D. P., Kent, E. C., and Kaplan, A.: Global analyses of sea surface temperature, sea ice, and night marine air temperature since the late nineteenth century, J. Geophys. Res.Atmos., 108, 4407, https://doi.org/10.1029/2002jd002670, 2003.

Rind, D., Lean, J., Lerner, J., Lonergan, P., and Leboissitier, A.: Exploring the stratospheric/tropospheric response to solar forcing, J. Geophys. Res.-Atmos., 113, D24103, https://doi.org/10.1029/2008jd010114, 2008.

Roscoe, H. K. and Haigh, J. D.: Influences of ozone depletion, the solar cycle and the QBO on the Southern Annular Mode, Q. J. Roy. Meteor. Soc., 133, 1855-1864, https://doi.org/10.1002/qj.153, 2007.

Roy, I.: The role of the Sun in atmosphere-ocean coupling, International Int. J. Climatol., 34, 655-677, https://doi.org/10.1002/joc.3713, 2014.

Roy, I. and Haigh, J. D.: Solar cycle signals in sea level pressure and sea surface temperature, Atmos. Chem. Phys., 10, 3147-3153, https://doi.org/10.5194/acp-10-3147-2010, 2010.

Roy, I. and Haigh, J. D.: The influence of solar variability and the quasi-biennial oscillation on lower atmospheric temperatures and sea level pressure, Atmos. Chem. Phys., 11, 11679-11687, https://doi.org/10.5194/acp-11-11679-2011, 2011.

Roy, I. and Haigh, J. D.: Solar Cycle Signals in the Pacific and the Issue of Timings, J. Atmos. Sci., 69, 1446-1451, https://doi.org/10.1175/jas-d-11-0277.1, 2012.

Salby, M. and Callaghan, P.: Connection between the solar cycle and the QBO: The missing link, J. Climate, 13, 2652-2662, https://doi.org/10.1175/15200442(1999)012<2652:cbtsca>2.0.co;2, 2000.

Scaife, A. A., Butchart, N., Warner, C. D., and Swinbank, R.: Impact of a spectral gravity wave parameterization on the stratosphere in the Met Office Unified Model, J. Atmos. Sci., 59, 1473-1489, https://doi.org/10.1175/15200469(2002)059<1473:ioasgw>2.0.co;2, 2002.

Scaife, A. A. and Smith, D.: A signal-to-noise paradox in climate science, npj Climate and Atmospheric Science, 1, 28, 2018.

Schmidt, H., Brasseur, G. P., and Giorgetta, M. A.: Solar cycle signal in a general circulation and chemistry model with internally generated quasi-biennial oscillation, J. Geophys. Res.-Atmos., 115, D00I14, https://doi.org/10.1029/2009jd012542, 2010.

Simpson, I. R., Blackburn, M., and Haigh, J. D.: The Role of Eddies in Driving the Tropospheric Response to Stratospheric Heating Perturbations, J. Atmos. Sci., 66, 1347-1365, https://doi.org/10.1175/2008jas2758.1, 2009. 
Smith, A. K. and Matthes, K.: Decadal-scale periodicities in the stratosphere associated with the solar cycle and the QBO, J. Geophys. Res.-Atmos., 113, D05311, https://doi.org/10.1029/2007jd009051, 2008.

Solanki, S. K., Krivova, N. A., and Haigh, J. D.: Solar Irradiance Variability and Climate, Annual Review of Astronomy and Astrophysics, Vol. 51:1, 311-351, 2013.

Soukharev, B. E. and Hood, L. L.: Solar cycle variation of stratospheric ozone: Multiple regression analysis of long-term satellite data sets and comparisons with models, J. Geophys. Res.Atmos., 111, D20314, https://doi.org/10.1029/2006jd007107, 2006.

SPARC: SPARC Assessment of Stratospheric Aerosol Properties (ASAP), edited by: Thomason, L. and Peter, Th., SPARC Report No. 4, WCRP-124, WMO/TD - No. 1295, available at: https:// www.sparc-climate.org/publications/sparc-reports/ (last access: 17 March 2019), 2006.

SPARC: SPARC CCMVal Report on the Evaluation of ChemistryClimate Models, edited by: Eyring, V., Shepherd, T., and Waugh, D., SPARC Report No. 5, WCRP-30/2010, WMO/TD No. 40, available at: https://www.sparc-climate.org/publications/ sparc-reports/ (last access: 17 March 2019), 2010.

SPARC: SPARC Report on the Lifetimes of Stratospheric Ozone-Depleting Substances, Their Replacements, and Related Species, edited by: Ko, M. K. W., Newman, P. A., Reimann, S., and Strahan, S. E., SPARC Report No. 6, WCRP-15/2013, available at: https://www.sparc-climate.org/ publications/sparc-reports/ (last access: 17 March 2019), 2013.

Stott, P. A., Jones, G. S., Lowe, J. A., Thorne, P., Durman, C., Johns, T. C., and Thelen, J. C.: Transient climate simulations with the HadGEM1 climate model: Causes of past warming and future climate change, J. Climate, 19, 2763-2782, https://doi.org/10.1175/jcli3731.1, 2006.

Sukhodolov, T., Rozanov, E., Ball, W. T., Bais, A., Tourpali, K., Shapiro, A. I., Telford, P., Smyshlyaev, S., Fomin, B., Sander, R., Bossay, S., Bekki, S., Marchand, M., Chipperfield, M. P., Dhomse, S., Haigh, J. D., Peter, T., and Schmutz, W.: Evaluation of simulated photolysis rates and their response to solar irradiance variability, J. Geophys. Res.-Atmos., 121, 6066-6084, https://doi.org/10.1002/2015jd024277, 2016.

Telford, P. J., Abraham, N. L., Archibald, A. T., Braesicke, P., Dalvi, M., Morgenstern, O., O'Connor, F. M., Richards, N. A. D., and Pyle, J. A.: Implementation of the Fast-JX Photolysis scheme (v6.4) into the UKCA component of the MetUM chemistry-climate model (v7.3), Geosci. Model Dev., 6, 161177, https://doi.org/10.5194/gmd-6-161-2013, 2013.
Tiao, G. C., Reinsel, G. C., Xu, D. M., Pedrick, J. H., Zhu, X. D., Miller, A. J., Deluisi, J. J., Mateer, C. L., and Wuebbles, D. J.: Effects of autocorrelation and temporal sampling schemes on estimates of trend and spatial correlation, J. Geophys. Res.-Atmos., 95, 20507-20517, https://doi.org/10.1029/JD095iD12p20507, 1990.

Tourpali, K., Zerefos, C. S., Balis, D. S., and Bais, A. F.: The 11 year solar cycle in stratospheric ozone: Comparison between Umkehr and SBUVv8 and effects on surface erythemal irradiance, J. Geophys. Res.-Atmos., 112, D12306, https://doi.org/10.1029/2006jd007760, 2007.

Trenberth, K. E.: The definition of El Nino, B. Am. Meteorol. Soc., 78, 2771-2777, https://doi.org/10.1175/15200477(1997)078<2771:tdoeno>2.0.co;2, 1997.

Tummon, F., Hassler, B., Harris, N. R. P., Staehelin, J., Steinbrecht, W., Anderson, J., Bodeker, G. E., Bourassa, A., Davis, S. M., Degenstein, D., Frith, S. M., Froidevaux, L., Kyrölä, E., Laine, M., Long, C., Penckwitt, A. A., Sioris, C. E., Rosenlof, K. H., Roth, C., Wang, H.-J., and Wild, J.: Intercomparison of vertically resolved merged satellite ozone data sets: interannual variability and long-term trends, Atmos. Chem. Phys., 15, 3021-3043, https://doi.org/10.5194/acp-15-3021-2015, 2015.

van Loon, H., Meehl, G. A., and Arblaster, J. M.: A decadal solar effect in the tropics in July-August, J. Atmos. Sol.-Terr. Phy., 66, 1767-1778, https://doi.org/10.1016/j.jastp.2004.06.003, 2004.

Wang, Y. M., Lean, J. L., and Sheeley, N. R.: Modeling the sun's magnetic field and irradiance since 1713, Astrophys. J., 625, 522-538, https://doi.org/10.1086/429689, 2005.

Webster, S., Brown, A. R., Cameron, D. R., and Jones, C. P.: Improvements to the representation of orography in the Met Office Unified Model, Q. J. Roy. Meteor. Soc., 129, 1989-2010, https://doi.org/10.1256/qj.02.133, 2003.

WMO (World Meteorological Organization): Scientific Assessment of Ozone Depletion: 2010, Global Ozone Research and Monitoring Project - Report No. 52, Geneva, Switzerland, 516 pp., 2011.

Yoo, C. and Son, S.-W.: Modulation of the boreal wintertime Madden-Julian oscillation by the stratospheric quasibiennial oscillation, Geophys. Res. Lett., 43, 1392-1398, https://doi.org/10.1002/2016GL067762, 2016. 